\title{
ASPECTOS QUÍMICOS DA BIOMINERALIZAÇÃO ÓSSEA
}

\author{
Marcos A.E. Cruz ${ }^{a}$, Claudio R. Ferreira ${ }^{a}$, Lucas F. B. Nogueira ${ }^{a}$, Luiz H.S. Andrillia ${ }^{\text {, Ana Lara N. dos Santos }}{ }^{\text {, }}$, Jeferson \\ M. M. Macedo ${ }^{a}$, Ekeveliny A. Veschi ${ }^{\mathrm{a}}$, Bruno Z. Favarin ${ }^{\mathrm{a}}$, Heitor G. Sebinelli, ${ }^{\mathrm{a}}$, Mayte Bolean ${ }^{\mathrm{a}}$, Ana Paula Ramos ${ }^{a *}$ e \\ Pietro Ciancaglini ${ }^{\mathrm{a} *}$,(1) \\ aDepartamento de Química, Faculdade de Filosofia, Ciências e Letras de Ribeirão Preto (FFCLRP) Universidade de São Paulo \\ (USP), 14040-901 Ribeirão Preto - SP, Brasil
}

Recebido em 29/07/2021; aceito em 12/11/2021; publicado em 14/01/2022

\begin{abstract}
THE CHEMISTRY BEHIND BONE BIOMINERALIZATION. The bone formation process is an example of how both time and nature acted harmonically to pave the path for life as we know. The unique association between calcium phosphate $(\mathrm{CaP})$ and collagen in a single building block, gave rise to one of the most remarkable biomaterials that we know. Our aim in this revision is to provide a brief glance at the different organization levels of the bone tissue, by describing the main their main features. We start with a brief discussion regarding the thermodynamic conditions for mineral formation and how living organisms surpass them. Then we present collagen, the major organic component of bone, in the light of its hierarchical organization as well as its association to CaP crystals. The mechanisms that control both mineral formation and the association with the organic phase are further presented, in which cells and other components of the extracellular matrix, such as matrix vesicles and noncollagenous proteins, become agents of bone construction. Finally, we underline the difficulty of studying the complex process of bone mineralization and present liposomes, proteoliposomes, and Langmuir monolayers as biomimetic approaches to this end.
\end{abstract}

Keywords: bone mineralization, collagen, calcium phosphate, matrix vesicles

\section{INTRODUÇÃo}

Muitos organismos, bem como seus constituintes, são formados por sistemas químicos complexos que envolvem a interação entre compostos orgânicos e inorgânicos ligados química e/ou fisicamente para gerar estruturas com propriedades aprimoradas. Tais organismos desenvolveram a habilidade de criar tecidos mineralizados a partir de precursores iônicos solúveis, que se associam para formar cristais dispersos em uma matriz extracelular composta por proteínas e/ ou polissacarídeos. ${ }^{1,2}$ Nessa matriz, moléculas orgânicas criam um arranjo tridimensional que fornece a informação estrutural e espacial para o direcionamento da nucleação e posterior crescimento da fase mineral. $\mathrm{O}$ processo pelo qual ocorre a formação de tecidos mineralizados é chamado de biomineralização. Por sua vez, os minerais encontrados nesses tecidos são comumente denominados biominerais. Diversos biominerais são encontrados na natureza como, por exemplo, a sílica presente em diatomáceas (um tipo de alga marinha), o carbonato de cálcio encontrado em conchas marinhas e o fosfato de cálcio presente na estrutura de dentes e ossos, que será o foco dessa revisão.

A formação de dentes e ossos é resultado da biomineralização de fosfatos de cálcio, que aqui chamaremos de ossificação. Mais precisamente, os biominerais que constituem esses tecidos são ortofosfatos de cálcio, formados primariamente pelo grupo ortofosfato $\left(\mathrm{PO}_{4}{ }^{3-}\right)$, podendo também apresentar as respectivas espécies ácidas $\left(\mathrm{HPO}_{4}{ }^{2-} \mathrm{e}_{2} \mathrm{PO}_{4}^{-}\right)$em suas estruturas. ${ }^{3} \mathrm{Em} \mathrm{pH}$ fisiológico $(\sim 7,4)$, íons fosfato, na sua forma livre, existem em equilíbrio com as formas $\mathrm{HPO}_{4}{ }^{2-}$ e $\mathrm{H}_{2} \mathrm{PO}_{4}{ }^{-}$em proporção $4: 1$, dessa forma, vamos nos referir a ambas as espécies por Pi (fosfato inorgânico). Na estrutura de ossos e dentes, proteínas, minerais e moléculas de água encontramse hierarquicamente associados, dando origem a um material com propriedades mecânicas e estruturais únicas. A complexidade desses tecidos mineralizados se deve não somente à interação finamente

*e-mail: pietro@ffclrp.usp.br; anapr@ ffclrp.usp.br controlada entre a parte orgânica e a parte inorgânica de suas matrizes, mas também às relações espaciais temporalmente reguladas entre todos seus componentes. Ossos e dentina compartilham uma matriz extracelular semelhante em composição mineral e proteica, enquanto o esmalte dentário difere dos ossos e dentes por seu alto teor mineral e matriz orgânica quase absente de colágeno, composta por amelogeninas, características essas que conferem resistência mecânica aprimorada a esse tecido. ${ }^{4}$

O tecido ósseo é um biocompósito constituído por aproximadamente $65 \%$ (em massa) de fase mineral, $25 \%$ de matéria orgânica e $10 \%$ de água. ${ }^{5}$ Sua fase mineral é formada por fosfato de cálcio, enquanto a parte orgânica é composta majoritariamente por colágeno do tipo-I e uma fração de proteínas não-colagenosas. O biomineral encontrado no tecido ósseo se assemelha em composição e estrutura à hidroxiapatita $\left[\mathrm{Ca}_{10}\left(\mathrm{PO}_{4}\right)_{6}(\mathrm{OH})_{2}\right]$, que em proporções estequiométricas possui razão molar $\mathrm{Ca} / \mathrm{P}=1,67$. Todavia, diferentes substituições iônicas (principalmente $\mathrm{CO}_{3}{ }^{2-}$, mas também outros íons como $\mathrm{Mg}^{2+}$, $\left.\mathrm{Sr}^{2+}, \mathrm{Cl}^{-}, \mathrm{F}^{-}, \mathrm{HPO}_{4}{ }^{2-}\right)$ e vacâncias na rede cristalina da hidroxiapatita ocorrem no tecido ósseo, resultando em baixa cristalinidade e quebra de estequiometria comparada ao valor de $\mathrm{Ca} / \mathrm{P}=1,67$. Dessa forma, é mais preciso referir-se à fase mineral do tecido ósseo como apatita biológica, ou simplesmente apatita, ${ }^{3}$ como será adotado neste texto. Além da sua composição química singular, cristais de apatita no tecido ósseo apresentam morfologia característica na forma de plaquetas, cujas dimensões variam em torno de 2-6 nm de espessura, 30-50 nm de largura e 60-100 nm de comprimento. . $^{6,7}$

Nesta revisão, focaremos na descrição da estrutura do tecido ósseo, tal como dos mecanismos bioquímicos que controlam sua formação. Abordaremos inicialmente aspectos fundamentais do processo de cristalização, de modo a compreender fatores físicoquímicos que controlam a formação da fase mineral. A associação íntima entre colágeno e apatita constitui o bloco construtor do tecido ósseo, cuja organização hierárquica evolui do nível molecular ao macroscópico. Mostraremos, na sequência, que a formação e a organização dessa matriz só é possível graças a eventos celulares 
altamente orquestrados que regulam e garantem a geração dos estímulos necessários para a ossificação. Por fim, apresentaremos modelos biomiméticos que podem ser utilizados para o estudo do processo de biomineralização, além de inspirarem o desenvolvimento de tecnologias e biomateriais para regeneração óssea.

\section{BIOMINERALIZAÇÃO: NUCLEAÇÃO E CRESCIMENTO DA FASE MINERAL}

Um dos maiores desafios da pesquisa atual em biomineralização é compreender a relação entre mecanismos físico-químicos e bioquímicos que possibilitam o controle extremamente preciso da formação de biominerais. Fundamentalmente, biomineralização é um processo no qual precursores iônicos solúveis sofrem uma transição de fase que parte de um estado de alta energia livre (estado solvatado dos precursores iônicos) para um estado de menor energia livre (a rede cristalina do biomineral resultante). Essa transição de fase é conhecida como nucleação. As bases físico-químicas da nucleação estão densamente descritas na literatura, ${ }^{8-10}$ de forma que, aqui, apresentaremos apenas uma visão simplificada do processo, sobre o qual alguns fatores essenciais podem ser delineados. O ponto básico é que, seja para a nucleação, quanto para o crescimento, a energia livre dos íons em solução deve ser maior que a soma das energias livre da fase mineral e da solução final. Logo, a força motriz para a formação mineral é a redução do potencial químico do sistema. Sendo mais preciso, a nucleação requer uma condição de metaestabilidade, onde a solução precursora existe em condição supersaturada. A supersaturação (S) de uma solução é definida como a razão entre o produto da concentração dos precursores solúveis e a sua respectiva constante de solubilidade (Kps), relativa à fase mineral formada. Dessa forma, para que ocorra nucleação, faz-se necessário o acúmulo de íons precursores tal que a condição para nucleação da fase mineral seja favorecida por uma supersaturação mínima $(S>1)$.

Enquanto o potencial químico da fase sólida for menor que o da solução, isto é, enquanto houver supersaturação, a partícula nucleada poderá crescer. $\mathrm{O}$ crescimento ocorre por meio da migração de espécies monoméricas da solução (sejam elas átomos, moléculas ou complexos moleculares) para um núcleo sólido, gerado a partir de flutuações termodinâmicas da solução. No entanto, apenas uma fração das partículas formadas por meio dessas flutuações se tornarão núcleos estáveis da fase sólida. Isso ocorre devido à tensão interfacial existente entre o núcleo formado e a solução, que se opõe à redução de energia livre gerada pela transferência de átomos da fase solvatada para a fase sólida. Assim, sob o ponto de vista termodinâmico, a formação da fase sólida consiste em sobrepor a barreira energética de formação do núcleo mais estável, que então evolui para a fase sólida final. Felizmente, a evolução dos organismos permitiu o desenvolvimento de mecanismos rebuscados para romper essas barreiras e promover a formação de tecidos mineralizados. Por essa razão, a visão da nucleação direta para a formação da fase mineral termodinamicamente mais estável nem sempre explica a complexidade dos panoramas energéticos envolvidos na biomineralização. ${ }^{2} \mathrm{As}$ condições biológicas, além de limitar os tipos de minerais que podem ser depositados a partir de soluções aquosas, promovem também um fino controle da fase cristalina e da morfologia final do sólido formado através da imposição/sobreposição de barreiras energéticas, sendo essas reguladas tanto espacial quanto temporalmente. Em virtude desse nível particular de controle, é comum fazermos referência a um controle cinético de precipitação, no qual modificações das barreiras energéticas de nucleação, crescimento e transição de fase, ditam a forma e a estrutura final do biomineral formado. ${ }^{11}$ Nesses casos, a cristalização geralmente se dá por um processo sequencial que envolve modificações estruturais e composicionais de precursores amorfos e intermediários cristalinos, ao invés de um caminho de etapa única onde o produto termodinâmicamente mais estável é prontamente formado (Figura 1). A extensão dessas transformações de fase depende das solubilidades das fases minerais intermediárias e das barreiras energéticas associadas às diferentes etapas, todas fortemente influenciadas por aditivos, sendo essa uma das razões que permite um alto controle do processo de formação do biomineral pela matriz orgânica. ${ }^{12}$ In vitro, sob condições fisiológicas de $\mathrm{pH}$ e concentração iônica, a formação de fosfato de cálcio reflete esse mecanismo de cristalização em várias etapas, como mostrado na Figura 1. Essa via de mineralização a partir de precursores metaestáveis em direção à formação da hidroxiapatita tem sido descrita também in vivo. ${ }^{13-15}$
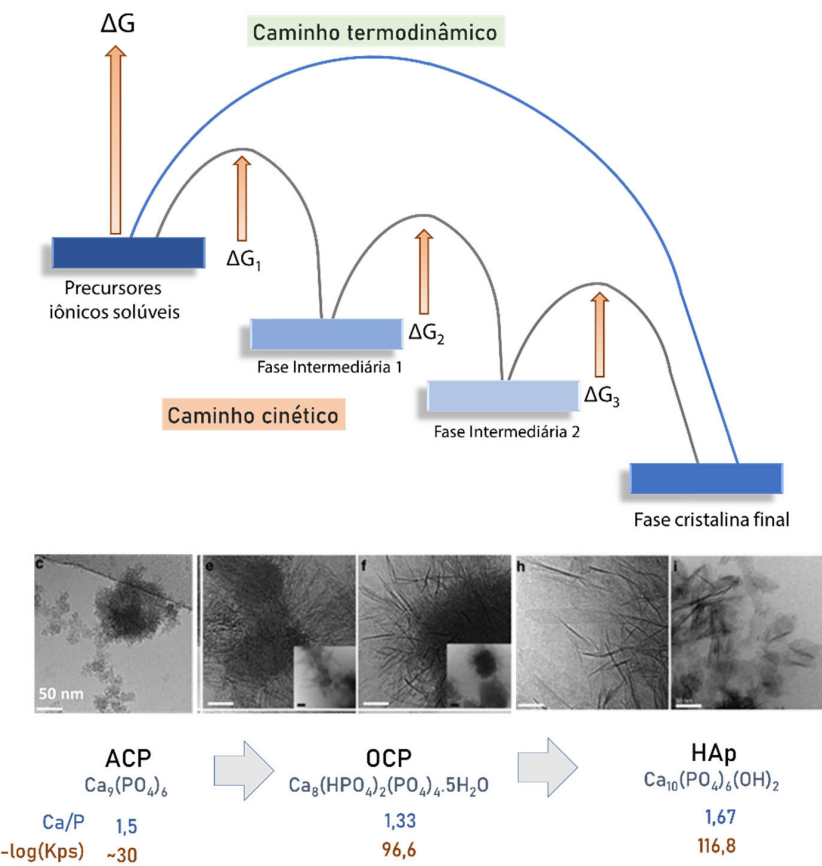

Figura 1. Caminhos de cristalização sob controles termodinâmico e cinético. Do ponto de vista termodinâmico, um sistema contendo precursores iônicos solúveis evolui para a formação direta da fase mais estável desde que seja rompida uma barreira de energia $(\Delta G)$ associada à nucleação e crescimento dessa fase. Todavia, é comum a existência de um caminho cineticamente controlado, no qual a precipitação sequencial ocorre a partir de precursores menos estáveis, controlada por barreiras energéticas $\left(\Delta G_{1,2,3}\right)$. O rota adotada para a formação de mineral, rota de etapa única (caminho termodinâmico) ou precipitação sequencial (caminho cinético), depende da magnitude das barreiras energéticas associadas à nucleação, crescimento e transformação de fases intermediárias ${ }^{11}$. Imagens de microscopia de eletrônica de transmissão dos produtos formados a partir de uma solução contendo $\mathrm{PO}_{4}{ }^{3-} e \mathrm{Ca}^{2+}$ ao longo do tempo ilustram essa precipitação sequencial, na qual fosfato de cálcio amorfo (ACP) é prontamente formado na solução, que então evolui para octacálciofosfato $(\mathrm{OCP})$ e, finalmente, hidroxiapatita (HAp). Note o aumento da razão Ca/P e a diminuição da solubilidade (Kps) ao longo da formação de HAp a partir dos seus precursores metaestáveis. Adaptado da referência ${ }^{16}$.

\section{O CONTROLE CELULAR DA OSSIFICAÇÃO}

Simplificadamente, a formação de tecidos mineralizados ocorre pela habilidade dos organismos de, simultaneamente, construírem uma matriz extracelular que servirá de alicerce para a deposição da fase mineral e secretarem um maquinário bioquímico capaz de controlar esse processo. ${ }^{17}$ Esse é o controle genético da biomineralização, no qual a existência de células fenotipicamente capazes de sintetizar e controlar a mineralização da matriz extracelular possibilitou o 
surgimento de tecidos mineralizados. Obviamente, a formação de tecidos mineralizados, como os do sistema esquelético, foi fundamental para a evolução das espécies pelo seu papel na proteção e locomoção, por exemplo. Além disso, os ossos desempenham outras funções importantes, tais como apoio para músculos esqueléticos, locais de nicho para síntese de células sanguíneas, armazenamento de íons minerais e secreção de hormônios. Outro ponto importante é que, apesar de sua aparência inerte e estática, ossos passam por um constante ciclo de remodelação de modo a manter a homeostase e funcionalidade da sua estrutura. Estima-se que durante os anos ativos de um adulto, a massa total da matriz óssea seja sintetizada e reabsorvida a cada cinco ou seis anos, obviamente com taxas diferentes dependendo da localização do osso e idade do indivíduo. ${ }^{18}$ De maneira simplista, esse processo é controlado pela ação de dois tipos celulares: os osteoblastos e os osteoclastos. Osteoblastos são as células responsáveis pela formação óssea, secretando colágeno do tipo I e outras biomoléculas capazes de controlar a mineralização da matriz extracelular. Osteoblastos aprisionados na matriz extracelular mineralizada se diferenciam em osteócitos, principal tipo celular encontrado em ossos maduros, que formam uma rede complexa (a rede lacuno-canalicular) com importante função na regulação da atividade óssea. ${ }^{19}$ Já os osteoclastos são as células responsáveis pela reabsorção da matriz calcificada. Essas células são capazes de criar um ambiente ácido produzido localmente para a degradação e reabsorção da matriz calcificada. ${ }^{20} \mathrm{~A}$ perturbação do equilíbrio entre a formação e a reabsorção óssea leva a condições patológicas. A formação óssea excessiva leva à supermineralização e excesso de massa óssea, como no caso da patologia denominada osteopetrose. ${ }^{21}$ Por outro lado, condições patológicas decorrentes de reabsorção óssea excessiva podem levar à fragilidade deste tecido, como no caso da osteoporose.

Por razões conceituais, é importante dar a dimensão correta ao termo "osso", já que podemos nos referir a ele tanto como um tecido (o conjunto formado por células ósseas e a matriz extracelular mineralizada) quanto um órgão (o osso como um todo, incluindo cartilagem, medula e vasos sanguíneos, por exemplo). Enquanto tecido, ossos podem ser formados por meio de duas vias de histogênese mecanisticamente distintas: a intramembranosa e a endocondral. ${ }^{18}$ Durante a ossificação intramembranosa, responsável pela formação embrionária de ossos chatos, como os da mandíbula e crânio, ocorre a condensação e a diferenciação de células mesenquimais progenitoras em osteoblastos. A condensação de células mesenquimais forma um molde que predefine a localização e o formato do osso futuro. Uma vez que as células mesenquimais se tornam comprometidas com o fenótipo osteoblástico, sua maturação leva à síntese da matriz óssea, onde osteoblastos expressam colágeno e enzimas/proteínas capazes de controlar a nucleação e a propagação da fase mineral. O tamanho e a forma final do osso são atingidos por meio de processos de remodelagem decorrentes da ação conjunta de osteoblastos e osteoclastos.

O outro tipo de ossificação, a endocondral, é um processo celular muito mais complexo que a ossificação intramembranosa, tanto em termos temporais quanto espaciais. Esse tipo de ossificação é responsável pela formação de ossos longos dos membros, como fêmur e tíbia. Durante a condensação das células mesenquimais que dita a forma e a localização do osso futuro (assim como no caso da intramembranosa), a diferenciação não ocorre diretamente em osteoblastos, mas em condrócitos (células específicas de cartilagem), que secretam uma matriz extracelular contendo colágeno (nesse caso colágeno do tipo II, em oposição ao colágeno do tipo I, majoritário em ossos maduros). Sendo assim, o que diferencia a ossificação endocondral da intramembranosa é a existência de um molde cartilaginoso, que precede a estrutura final do osso. Neste molde, os condrócitos proliferam, diferenciam-se e alteram suas funções celulares ao atingir o estado de hipertrofia, que possui fenótipo mineralizante. Esse processo resulta na formação de cartilagem mineralizada, que apresenta uma fase mineral pouco cristalina dispersa na matriz de colágeno. Inicia-se então o processo de degradação dessa matriz, onde osteoclastos (ou mais precisamente condroclastos, por serem células da cartilagem) promovem a remoção do conteúdo da cartilagem calcificada, criando vacâncias na matriz degradada. Esses espaços tornam-se ocupados por novas células progenitoras que, desta vez, diferenciam-se em osteoblastos, e sintetizam uma nova matriz extracelular que será posteriormente calcificada e dará origem à estrutura final do osso. A formação óssea é ainda acompanhada por uma alta vascularização da região em crescimento. A invasão por vasos sanguíneos é importante para a entrega de células, nutrientes e de precursores iônicos à matriz. ${ }^{22} \mathrm{~A}$ dependência entre o desenvolvimento do tecido ósseo e a presença de oxigênio é extremamente complexa. Pequenas alterações no nível de oxigênio que atinge o tecido ósseo afetam sua homeostase e por consequência seu metabolismo. ${ }^{23}$ Por exemplo, a limitação de oxigênio à qual condrócitos são submetidos durante a ossificação endocondral gera um estado de hipóxia que controla finamente o metabolismo celular e a subsequente mineralização da matriz extracelular. $^{24}$

A primeira matriz sintetizada pelos osteoblastos é denominada tecido ósseo primário, no qual a formação e mineralização da matriz é relativamente rápida e desorganizada, dando origem a fibras de colágeno com pouca ou nenhuma orientação preferencial. ${ }^{25} \mathrm{O}$ tecido ósseo primário é transiente, sendo substituído pelo processo de remodelagem, que gera o tecido ósseo secundário, ou lamelar. O tecido ósseo lamelar é caracterizado por uma rede densa de fibras de colágeno paralelamente alinhadas dentro de cada lamela, mas com orientação alternada entre as lamelas. ${ }^{25}$ Acredita-se que, para a formação do tecido lamelar, osteoblastos se distribuem de forma polarizada ao longo da superfície da matriz em remodelação e secretam fibrilas de colágeno em uma orientação paralela à essa superfície, dando origem à alta organização espacial das fibrilas de colágeno observadas no tecido ósseo maduro. ${ }^{26}$ Ao discutir a estrutura extraordinária dos ossos, a literatura especializada geralmente se refere à hierarquia do tecido ósseo secundário maduro, que descreveremos a seguir.

\section{ESTRUTURA DO TECIDO ÓSSEO}

\section{Formação e arranjo tridimensional da fibrila de colágeno mineralizada}

A arquitetura óssea é dependente de vários fatores, sendo variável entre espécies, idade e localização do osso no organismo. Quando discutimos a singularidade da estrutura óssea, estamos nos referindo à organização multiescalar e hierárquica entre fibrilas de colágeno mineralizadas, que se associam dando origem à uma estrutura complexa que pode ser desmembrada, de forma simplificada, em 7 níveis organizacionais ${ }^{5}$ (Figura 2). Vale ressaltar que com o avanço das técnicas de microscopias com resolução em nível nanométrico, outros níveis organizacionais puderam ser definidos na descrição do material ósseo, especialmente no que tange aos arranjos entre colágeno e cristais de apatita. ${ }^{25,27}$

Partindo do osso como um órgão (Figura 2, Nível 7), a primeira distinção organizacional pode ser realizada mesmo a olho nu, onde facilmente distingue-se a morfologia do tecido ósseo esponjoso (ou trabecular) da do tecido ósseo compacto (ou cortical), ambos representados pelo Nível 6, na Figura 2. Enquanto o tecido esponjoso possui uma estrutura porosa com um arranjo desordenado e interconectado de trabéculas, o tecido ósseo compacto é denso e 
formado por estruturas cilíndricas concêntricas chamadas ósteons (Figura 2, Nível 5). Estruturalmente, ambos os tecidos compacto e esponjoso são formados por lamelas, que são arranjos tridimensionais de fibras de colágeno da ordem de algumas dezenas de micrômetros (Figura 2, Nível 4). Uma fibra é um arranjo supramolecular de fibrilas de colágeno, no qual todas encontram-se orientadas ao longo de um eixo comum. Os arranjos lamelares de fibras de colágeno podem ser altamente organizados, como nos ósteons, onde lamelas são dispostas concentricamente, ou lamelas dispostas de modo menos ordenado, como no osso esponjoso. A característica básica das lamelas é a disposição unidirecional de fibras de colágeno (Figura 2, Nível 3). Por fim, chegamos ao nível nanométrico, onde fibrilas de colágeno mineralizadas emergem como o bloco construtor do material ósseo (Figura 2, Nível 2).

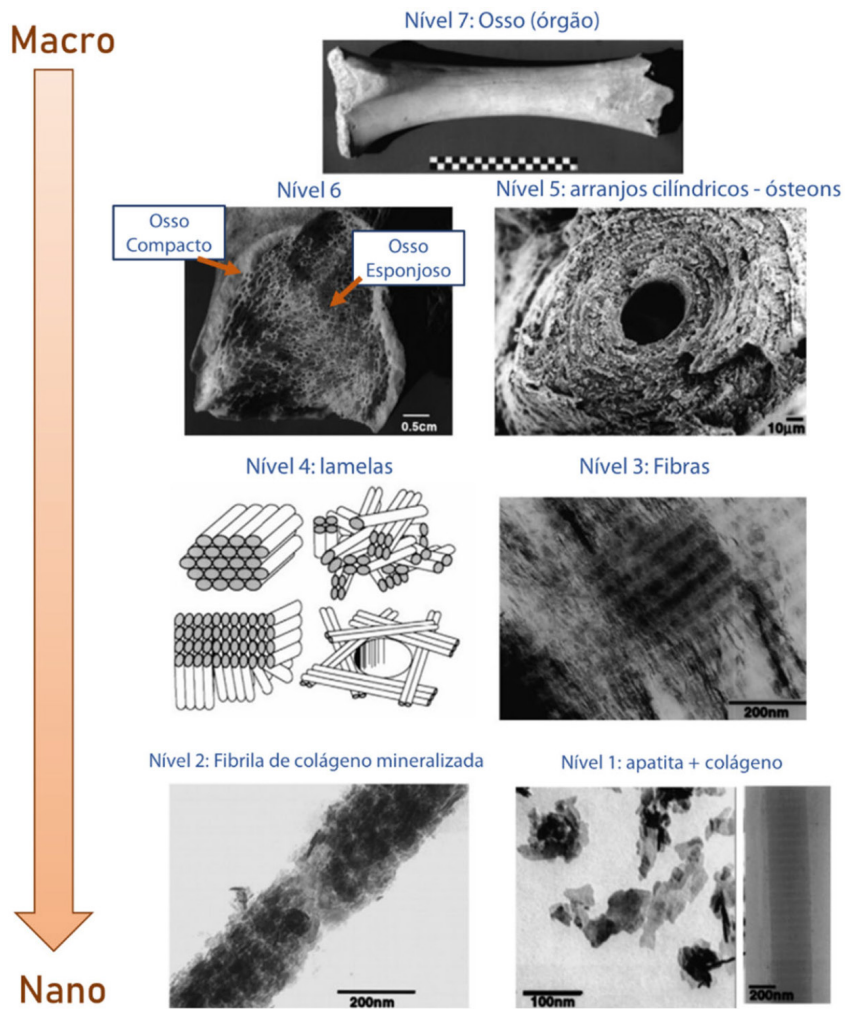

Figura 2. Os 7 níveis hierárquicos do osso. Nível 1: Cristais isolados de apatita extraídos de osso humano (lado esquerdo) e fibrila de colágeno não-mineralizada (lado direito) observados por microscopia eletrônica de transmissão (MET). Nível 2: imagem obtida por MET de uma fibrila de colágeno mineralizada do tendão de peru. Nível 3: micrografia MET de uma seção fina do tendão de peru mineralizado. Nível 4: Quatro padrões de organização de matriz lamelar de fibrilas encontrados no osso. Nível 5: imagem obtida por microscopia eletrônica de varredura (MEV) de um ósteon de osso humano. Nível 6: corte transversal de um fêmur humano fossilizado (cerca de 5.500 anos). Nivel 7: Osso bovino inteiro. Adaptado da referência. ${ }^{5}$

Uma questão central da pesquisa em biomineralização óssea é entender como as células controlam a formação da fibrila de colágeno mineralizada e a automontagem desse bloco em estruturas tridimensionais com alto nível hierárquico. Apesar de muita evolução no conhecimento produzido nessa área, ainda não há um consenso acerca do mecanismo preciso da ossificação. Em todo caso, a compreensão desse processo inicia-se na análise dos componentes isolados da matriz óssea, ou seja, fibrilas de colágeno e cristais de apatita (Figura 2, Nível 1).

\section{A ultraestrutura da fibrila de colágeno}

A superfamília de colágenos, que compreende 28 tipos, classificados por sua composição polipeptídica e arranjo supramolecular, representa a principal classe de proteínas estruturais formadoras de matriz extracelular em diferentes espécies ${ }^{28}$. Dentre os diferentes tipos de colágenos, os chamados fibrilares são os que mais se destacam por sua complexidade organizacional e função, sendo encontrados em diferentes tecidos, como na córnea (tipos I e III), cartilagem (tipo II) e osso (tipo I). A unidade básica que caracteriza as proteínas colagenosas é a existência da tripla-hélice de colágeno, formada pelo entrelaçamento de três cadeias alfa $(\alpha)$. A sequência polipeptídica e os tipos de cadeias $\alpha$ que formam a tripla-hélice é o que confere a diversidade estrutural dos diferentes tipos de colágeno. Por exemplo, a tripla-hélice do colágeno tipo I é formada pela associação entre duas cadeias do tipo $\alpha_{1}$ (I) e uma cadeia do tipo $\alpha_{2}$ (II). Por outro lado, o colágeno do tipo II é formado pelo entrelaçamento de três cadeias do tipo $\alpha_{2}$ (II). Cada cadeia $\alpha$ apresenta seus aminoácidos constituintes dispostos em uma sequência primária dada pela repetição consecutiva da trinca glicina-X-Y, onde glicina está sempre presente na terceira posição, e X/Y são ocupados por diferentes aminoácidos. Apesar dessas posições serem passíveis de ocupação por qualquer aminoácido, cerca de $22 \%$ dos resíduos diferentes de glicina são prolina ou hidroxiprolina, um aminoácido derivado da prolina resultante de modificações pós-traducionais (adição de grupos hidroxila na cadeia lateral do aminoácido). ${ }^{29} \mathrm{~A}$ ocorrência de glicina a cada terceira posição é essencial, pois é o aminoácido com a menor cadeira lateral (apenas um átomo de $\mathrm{H}$ ), favorecendo o entrelaçamento altamente compacto das três cadeias alfa que formam a tripla-hélice. Neste arranjo, a cadeia lateral dos resíduos de glicina é projetada para o centro da hélice, enquanto as cadeias laterais dos demais resíduos de aminoácidos são expostas para o meio externo à tripla-hélice (Figura $3 b$ ). Esse ordenamento singular cria motivos estruturais fundamentais que suportam o papel biológico do colágeno na matriz extracelular, uma vez que esse arranjo específico de aminoácidos gera pontos de ligação para diferentes macromoléculas. ${ }^{28} \mathrm{~A}$ tripla-hélice de colágeno é estabilizada por interações fracas, principalmente por ligações de hidrogênio envolvendo o grupo amino do resíduo de glicina e os grupos carboxílicos de resíduos de aminoácidos presentes nas cadeias $\alpha$. A importância do resíduo de glicina na terceira posição da sequência polipeptídica é reafirmada pela existência de diversas patologias genéticas associadas a alterações desta localização. ${ }^{28}$ Como exemplo, pode ser destacada a osteogênese imperfeita, também conhecida como doença dos ossos de vidro, cuja principal característica é a extrema fragilidade dos ossos.

A molécula de colágeno (denominada tropocolágeno) é formada por uma tripla-hélice que possui cerca de $300 \mathrm{~nm}$ de comprimento e $300 \mathrm{kDa}$ de massa molecular. Todavia, colágeno não é encontrado na forma de moléculas isoladas na matriz extracelular. Na verdade, uma característica fundamental desse grupo de proteínas é a sua capacidade de se auto-organizarem em arranjos supramoleculares ${ }^{31}$ (Figura 3a). Na matriz extracelular do tecido ósseo, colágeno é encontrado na forma de fibrilas (espessura da ordem de $100 \mathrm{~nm}$ e comprimento de até $1 \mu \mathrm{m}$ ), que são arranjos supramoleculares onde moléculas de colágeno estão dispostas de forma alinhada ao longo de um eixo. A organização axial das moléculas de colágeno foi elucidada por Hodge-Petruska em 1964, a partir de análises de MET de fibrilas de colágeno reconstituídas in vitro. ${ }^{32}$ Utilizando contraste por elementos eletrodensos, notou-se a existência de um padrão de repetitivo no qual uma banda clara intercala com outra escura a cada $\sim 67 \mathrm{~nm}$, ao longo de toda a fibrila. Hodge-Petruska, ${ }^{32}$ então, propuseram que este padrão característico surge do espaçamento (chamado de espaçamento D), entre diferentes moléculas de colágeno, 
a.

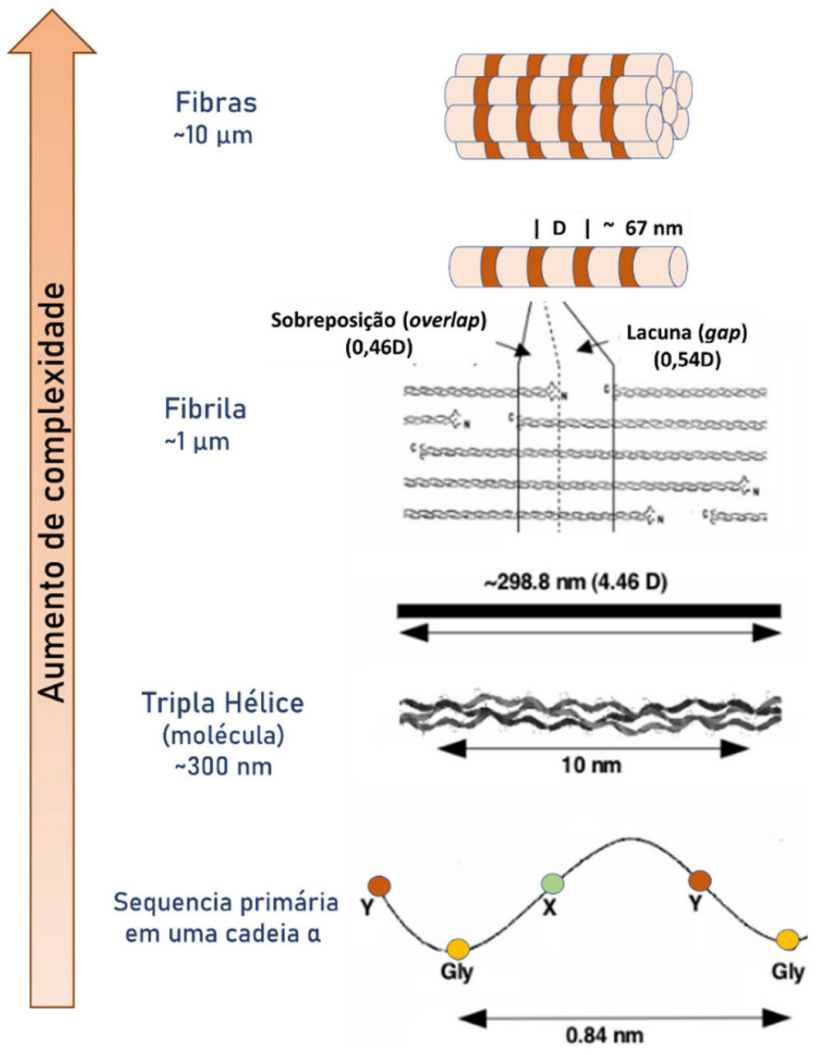

b.
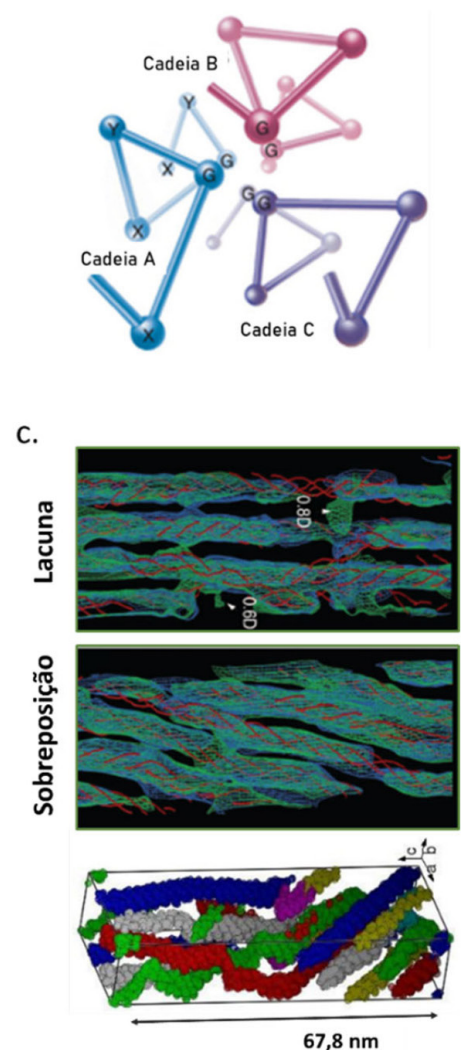

Figura 3. Organização multiescalar do colágeno. (a) Visão esquemática do ordenamento hierárquico do colágeno, variando da estrutura primária em escala molecular até fibras de colágeno com comprimentos da ordem de $10 \mu \mathrm{m}$. (b) Na tripla hélice de colágeno, as três cadeias polipeptídicas se entrelaçam de tal forma que seus resíduos de glicina estão dispostos para o interior da molécula, maximizando as interações intermoleculares que estabilizam a estrutura. (c) Mapas de densidade eletrônica de fibrilas de colágeno obtidos por cristalografia. O arranjo axial entre diferentes moléculas de colágeno dá origem à fibrila, que são arranjos alternados entre regiões de sobreposição e de lacuna. Imagem adaptada da referência. ${ }^{30}$

cujo comprimento não é um múltiplo inteiro de $\mathrm{D}$, mas em torno de 4,46xD. Nesse modelo, cada molécula de colágeno é considerada como um bastão rígido de comprimento fixo $(300 \mathrm{~nm})$. Ao longo do eixo da fibrila as moléculas de colágeno estão paralelamente dispostas e deslocadas entre si. Note na Figura 3a, que devido ao distanciamento entre as moléculas ao longo do eixo da fibrila, há sobreposições axiais entre as moléculas, além de regiões onde existem vacâncias geradas em função do espaçamento entre duas moléculas vizinhas. Assim, surgem as regiões de sobreposição (em inglês overlap, com dimensão de $0,46 \mathrm{xD}$ ) e de lacuna (em inglês gap, com dimensão de $0,54 \mathrm{xD}$ ). A coloração das bandas observadas por MET surge do processo de contraste com elementos eletrodensos que penetram mais facilmente em regiões de menor empacotamento das moléculas (as 'lacunas'), criando as bandas escuras, enquanto as bandas claras representam as regiões de sobreposição. Apesar desse modelo simplista de Hodge-Petruska ser válido até hoje, o uso de técnicas avançadas de cristalografia permitiu a obtenção de mais detalhes da microestrutura da fibrila de colágeno. ${ }^{7,30}$ Ao invés de bastões rígidos, Orgel et al.$^{30}$ revelaram uma superestrutura muito mais complexa para a fibrila de colágeno, na qual as moléculas de tropocolágeno não se encontram perfeitamente alinhadas, mas organizadas em um arranjo torcido e inclinado. $\mathrm{O}$ escalonamento entre as moléculas leva à estrutura de bandas periódicas característica das fibrilas de colágeno, contendo uma região de sobreposição densa e uma região de lacuna menos compacta. $^{30}$

A natureza fibrilar do colágeno, principalmente pela existência de sítios de ligação especificamente arranjados a nível molecular, ${ }^{28}$ permite a auto-organização lateral das fibrilas, dando origem a um arranjo da ordem de dezenas de micrômetros, conhecido como fibras. Na realidade, acredita-se que a habilidade das moléculas de colágeno formar arranjos supramoleculares seja fundamental para a estabilidade dessa proteína em condições fisiológicas. ${ }^{33}$ Em cada fibra, arranjos extensos de fibrilas lateralmente organizadas são estabilizados por ligações covalentes. O modo como as fibras de colágeno se associa é o que dá origem à organização hierárquica presente em tecidos baseados nessa proteína, como em lamelas no caso do tecido ósseo (ver Figura 2). Nota-se nas imagens de MET de uma lamela do tecido ósseo (nível 3 da Figura 2), que o padrão repetitivo de bandas das fibrilas de colágeno individuais é propagado ao longo das fibras (onde verifica-se a existência de bandas precisamente posicionadas ao longo de centenas de nanômetros). Apesar da estrutura de fibrilas de colágeno individuais ser bem conhecida, pouco ainda se sabe sobre o modo pelo qual essas fibrilas se organizam em arranjos tridimensionais em nível tecidual, onde fibras de colágeno altamente organizadas atingem dimensões micrométricas. ${ }^{34}$ Além disso, a complexidade supramolecular e organização estrutural das fibras de colágeno é específica para cada tipo de tecido, assim como o grau de reticulação e glicosilação, e a combinação entre diferentes tipos de colágeno, fatores esses que ditam a estrutura final e a função do tecido. $^{35}$

\section{O CONTROLE FISICO-QUÍMICO DA OSSIFICAÇÃO}

Ainda que vários estudos tenham se proposto a elucidar os caminhos que determinam onde, quando e como os cristais de apatita se formam e se associam às fibrilas de colágeno durante a ossificação, 
o mecanismo exato do processo ainda é obscuro. Inicialmente, por volta da década de 1920, foi proposta uma teoria de cristalização homogênea para a ossificação. Acreditava-se que células osteogênicas eram responsáveis por aumentar localmente as concentrações dos íons precursores da apatita $(\mathrm{Ca}, \mathrm{Pi})$, por meio da ação de enzimas, até um nível suficientemente alto de supersaturação que resultasse na nucleação homogênea e espontânea de cristais de apatita em tecidos mineralizados. ${ }^{36}$ Todavia, com a evolução das técnicas de microscopia para análise do tecido ósseo, observou-se que havia uma relação íntima entre as fibrilas de colágeno e a fase mineral. Em 1952, Robinson e Watson ${ }^{6}$ mostraram que as células unitárias dos cristais de apatita possuem eixo c quase paralelo ao eixo da fibrila de colágeno, dando origem à ideia de que uma associação específica entre colágeno e a fase mineral era predominante na formação óssea. Estudos posteriores demonstraram que os cristais de apatita estão localizados principalmente no interior das fibrilas, preferencialmente nucleados a partir das regiões de lacuna, formando arranjos onde os cristais, na forma de plaquetas, estão quase que uniformemente empilhados ao longo do eixo da fibrila. ${ }^{37-39}$ Essas observações da ultraestrutura do tecido ósseo puseram em xeque a ideia da precipitação homogênea, na qual cristais seriam formados aleatória e espontaneamente pelo simples aumento local da supersaturação, e possibilitaram o desenvolvimento do modelo de nucleação heterogênea, onde a formação da fase mineral é controlada pela existência da matriz orgânica (fibrilas de colágeno e proteínas não-colagenosas, por exemplo). ${ }^{40}$

É consenso na literatura especializada atual que a ossificação é controlada pela matriz orgânica, no entanto, diferentes modelos têm sido propostos para explicar a origem da fase mineral e o papel do colágeno e de diferentes biomoléculas durante o processo..$^{40,41} \mathrm{O}$ panorama atual da ossificação é que a mineralização começa quando precursores minerais entram nas regiões de lacuna de colágeno, a partir do qual cristais de apatita são nucleados e se orientam com seus eixos c paralelos ao longo eixo das fibrilas de colágeno. ${ }^{7}$ Esses minerais crescem fora das dimensões de uma única fibrila de colágeno, formando um padrão contínuo de cristais intrafibrilares e extrafibrilares. ${ }^{27}$ Todavia, a grande questão que ainda perdura na literatura especializada é a origem dos precursores minerais. A ideia mais simples é a de que o colágeno por si só seja o protagonista no controle da mineralização, onde as regiões de lacuna das fibrilas permitem que $\mathrm{Ca}^{2+}$ e $\mathrm{Pi}$ se acumulem, atingindo a supersaturação necessária para a nucleação de apatita. ${ }^{42,43}$ Mas, evidencias experimentais tem apontado que caminhos mais complexos possam existir. Evidências experimentais têm indicado a possibilidade de diferentes caminhos, como a nucleação mediada por grupos carregados do colágeno, ${ }^{44,45}$ por meio de estruturas vesiculares, ${ }^{14,46-48}$ ou ainda pela participação de complexos proteína-mineral circulantes no fluido extracelular. ${ }^{49,50}$ Além disso, grande esforço tem sido empregado na compreensão da mineralização intrafibrilar ${ }^{40,41} \mathrm{e}$ pouco ainda se sabe acerca da origem do controle na organização do cristais extrafibrilares, que pode estar associado ao caráter denso da matriz colagenosa que direciona e cria o confinamento onde ocorre a deposição dos cristais..$^{51,52}$

A ideia de que a formação da fase mineral ocorreria pela existência de um precursor mineral amorfo surgiu na década de 1960, com a análise da composição do tecido ósseo em diferentes estágios de formação. ${ }^{53}$ Esses estudos demonstraram que a ossificação não ocorria pela precipitação direta em apatita cristalina, mas a partir de precursores menos solúveis que são consumidos à medida que o osso é calcificado e sofre maturação. Foi proposta, então, a existência de fosfato de cálcio amorfo (ACP) como um precursor transiente da apatita cristalina encontrada no tecido ósseo maduro. Essa ideia foi corroborada por estudos in vitro de precipitação de fosfatos de cálcio em solução, os quais mostraram que, em condições de $\mathrm{pH}$, temperatura e composição próximas às fisiológicas, os primeiros precipitados eram amorfos e se convertiam em apatita cristalina. ${ }^{54,55}$ Analisando a composição de ACP formado in vitro, Posner ${ }^{56}$ propôs que ACP é formado pelo arranjo de subunidades de fórmula $\mathrm{Ca}_{9}\left(\mathrm{PO}_{4}\right)_{6}$, entidades conhecidas como clusters de Posner. Esses clusteres seriam os precursores da formação de ACP. A existência dos clusters de Posner foi validada com uso de técnicas avançadas de microscopia. ${ }^{16,57}$ Sua estrutura foi revisitada como complexos de associação iônica de fórmula geral $\left[\mathrm{Ca}\left(\mathrm{HPO}_{4}\right)_{3}\right]^{4-}$, refletindo que essas entidades não representam, de fato, uma unidade estrutural fixa, mas que a composição química desses blocos de construção progride gradativamente em direção à do produto final (apatita). ${ }^{16}$ $\mathrm{Na}$ realidade, grupos carregados da matriz orgânica exercem papel fundamental na estabilização dessas entidades precursoras, ${ }^{57,58}$ diminuindo a barreira energética a ser ultrapassada para a nucleação de ACP e posterior evolução à apatita. A existência de intermediários que precedem a formação de apatita vai ao encontro da ideia de que a biomineralização segue um caminho "não-clássico", descrito por um equilíbrio entre o controle cinético e termodinâmico do processo: a formação e estabilização de fases precursoras termodinamicamente favorecidas em relação aos íons constituintes livres, diminuindo a barreira de energia necessária para a nucleação de ACP, e por consequência facilitando a formação final de apatita. ${ }^{59-61}$ Essas observações mostram que a precipitação de fosfato de cálcio in vitro é controlada cineticamente, o que significa que o mineral não se forma diretamente como produto termodinamicamente mais estável (relembre a Figura 1). Ao invés disto, o mineral precipita primeiro como a forma cineticamente mais acessível, neste caso ACP, que subsequentemente se transforma na fase termodinamicamente mais estável (apatita). ${ }^{13}$ A existência do precursor amorfo durante a formação óssea foi demostrada in vivo, como já observado utilizandose calvaria de rato ${ }^{15}$ e em cauda de peixe-zebra, ${ }^{62,63}$ por exemplo. A estratégia da natureza de usar precursores metaestáveis para controlar a formação mineral é comumente encontrada na biomineralização. ${ }^{64}$

Entretanto, qual a origem do precursor amorfo e qual sua relação com a mineralização das fibrilas de colágeno? Para responder essa questão, muito tem sido estudado sobre a participação de proteínas não-colagenosas (PNC) durante o processo. PNC, como por exemplo a osteocalcina, osteopontina e sialoproteína óssea, são um dos principais componentes orgânicos, além do colágeno, encontrados no osso. ${ }^{65} \mathrm{Na}$ matriz extracelular do osso, colágeno é a proteína mais abundante em termos de massa, porém em termos de quantidades molares, PNC são tão abundantes quanto, atestando que estas exercem papel significativo na estrutura do osso. ${ }^{66}$ As principais características dessas proteínas são o grau elevado de fosforilação e a abundância de resíduos ácidos como serina, ácido aspártico e ácido glutâmico. ${ }^{65,67}$ Acredita-se que a presença dessas proteínas na matriz extracelular possa controlar vários aspectos da mineralização, especificamente por meio de mecanismos de inibição e promoção do processo pela interação entre seus grupos carregados e a fase mineral nascente. ${ }^{65,67}$ Além disso, resíduos fosforilados nessas proteínas podem atuam como motivos estruturais para a interação com a matriz de colágeno. ${ }^{68,69}$ Diferentes estudos utilizando-se proteínas nãocolagenosas isoladas mostraram a influência dessas macromoléculas no controle da formação de apatita in vitro. A presença de grupos carregados atua tanto como pontos de nucleação pelo aumento local de supersaturação, ${ }^{57}$ quanto como inibidor, por meio da ligação à fase mineral nascente, impedindo a captação de íons precursores adicionais necessários para o crescimento do mineral. ${ }^{70}$ Evidências in vivo do papel das proteínas não-colagenosas durante a calcificação surgem a partir da localização preferencial dessas proteínas em tecidos mineralizados e de experimentos de deleção gênica, que 
demostraram falhas na mineralização devido a alterações na expressão dessas proteínas. Todavia, muitas proteínas não-colagenosas (como a osteopontina), exercem outras funções nos organismos além do controle da calcificação, dificultando a interpretação dos resultados observados. ${ }^{66}$ Essas dificuldades tornaram necessária a criação de modelos biomiméticos simplificados para o estudo do efeito de proteínas não-colagenosas durante a mineralização. ${ }^{71}$

Gower et al..$^{72}$ desenvolveram um modelo com o uso de polímeros negativamente carregados (ácido poliaspártico, por exemplo) para mimetizar o papel das proteínas não-colagenosas durante a calcificação. A partir deste trabalho seminal, diferentes estudos se dedicaram à avaliação do efeito de proteínas não-colagenosas no controle da mineralização intrafibrilar do colágeno. ${ }^{7,73-76} \mathrm{~A}$ mistura de $\mathrm{Ca}^{2+}$ e Pi promoveu a precipitação de $\mathrm{ACP}$, precursor de apatita, sob condições iniciais específicas $(\mathrm{pH}$, temperatura, e concentrações de $\mathrm{Ca}^{2+}$ e Pi).$^{54}$ Porém, neste estudo, a adição de um polímero negativamente carregado à solução inibiu a transformação em apatita, devido à estabilização do precursor amorfo, ACP. A interação do polímero com o mineral resultou na formação de um complexo negativamente carregado, capaz de interagir eletrostaticamente com uma região específica da fibrila de colágeno, um domínio positivamente carregado na extremidade C-terminal da zona de lacuna, mediando assim a infiltração do ACP no interior da fibrila, que posteriormente se transforma em apatita cristalina. ${ }^{73} \mathrm{~A}$ ultraestrutura da região de lacuna (relembre a Figura 4c) fornece canais intermoleculares que, por efeito de confinamento, controlam e definem o tamanho e a orientação dos cristais de apatita formados no interior da fibrila. ${ }^{7} \mathrm{~A}$ infiltração da fase precursora amorfa na fibrila de colágeno é resultado de um balanço entre interações eletrostáticas e equilíbrio osmótico. ${ }^{74}$ Apesar desse modelo in vitro permitir a compreensão da mineralização intrafibrilar e inspirar metodologias para o desenvolvimento de biomateriais para regeneração óssea, ${ }^{77,78}$ pouco ainda se sabe acerca do que controla a organização dos cristais extrafibrilares e, mais importante, a sua organização nos níveis superiores de hierarquia da matriz óssea. É válido ressaltar que esse modelo in vitro não implica que, in vivo, a infiltração de proteínas não-colagenosas ocorra no interior das fibrilas de colágeno. $\mathrm{Na}$ realidade, a fibrila de colágeno atua como uma barreira, através da qual moléculas menores que $6 \mathrm{kDa}$ podem difundir-se livremente, enquanto moléculas maiores que $40 \mathrm{kDa}$ são excluídas do interior da fibrila. ${ }^{79}$ Exceto no caso da osteocalcina, que por seu tamanho de apenas 5,6 kDa, poderia ser encontrada infiltrada na região de lacuna da fibrila de colágeno. Desta forma, o papel atribuído às proteínas não-colagenosas seria tanto na nucleação (atuando como esponjas de cálcio, aumentando localmente a supersaturação) como na estabilização do precursor amorfo, permitindo sua posterior infiltração no interior da fibrila, onde complexos minerais podem difundir-se livremente. ${ }^{80}$

\section{O CONTROLE BIOQUÍMICO DA OSSIFICAÇÃO}

Íons estão presentes em todo o nosso corpo, circulando pelo fluido extracelular. A concentração de $\mathrm{Ca}^{2+}$ no meio extracelular é finamente controlada pelo sistema endócrino, que mantém seus valores na faixa estreita de 2,2 a 2,7 mmol L $\mathrm{m}^{-1}{ }^{81}$ Já a concentração de Pi varia consideravelmente com a idade, sendo maior durante a infância, mas com valores na faixa de 1,12 a $1,45 \mathrm{mmol} \mathrm{L}^{-1}$ na fase adulta ${ }^{82}$ Em termos puramente químicos, um mineral precipitará

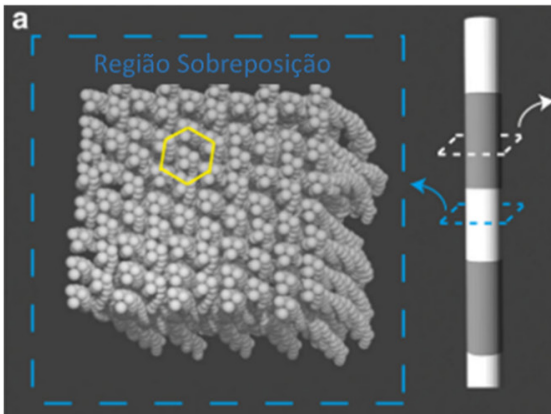

b
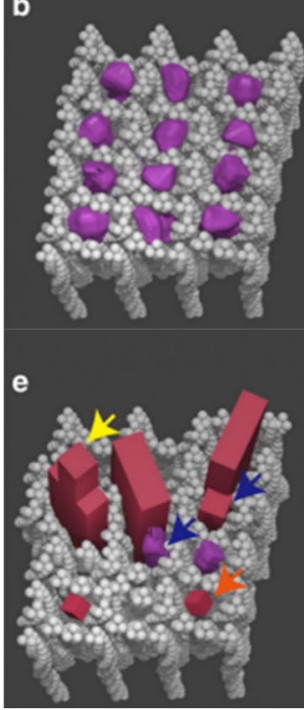

C

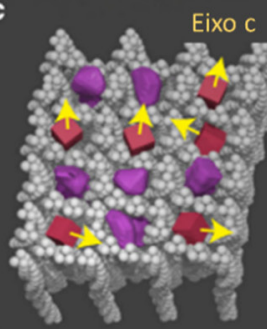

f

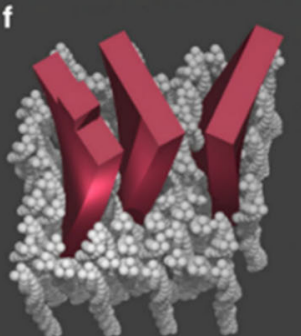

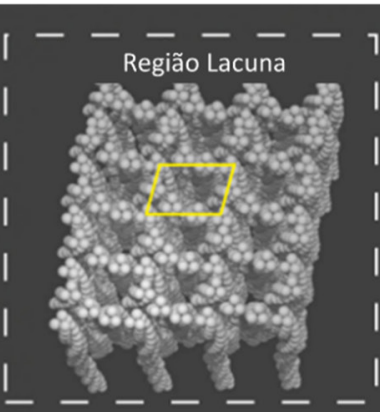

d

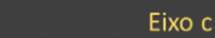

Eixo $c$
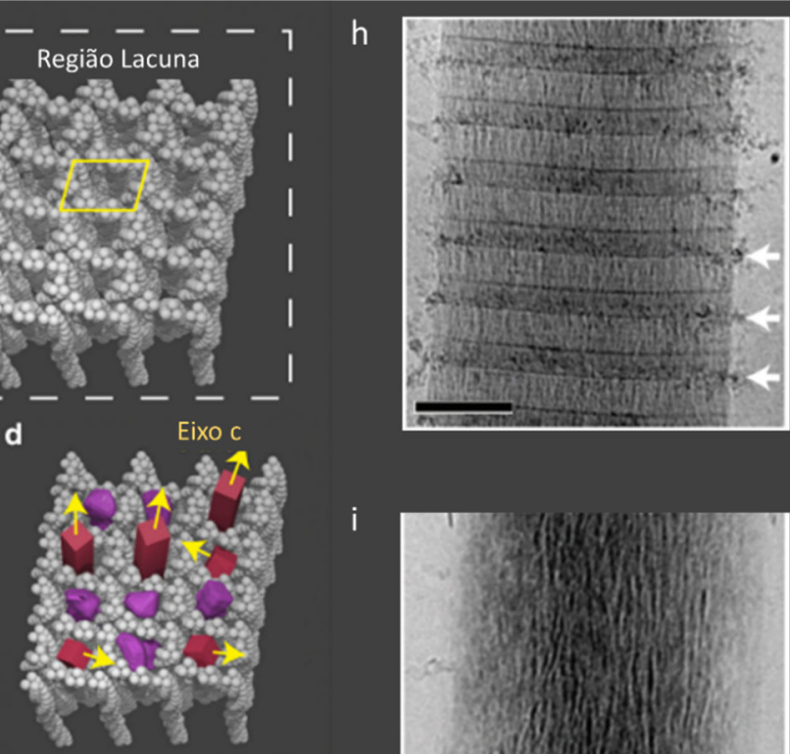

g
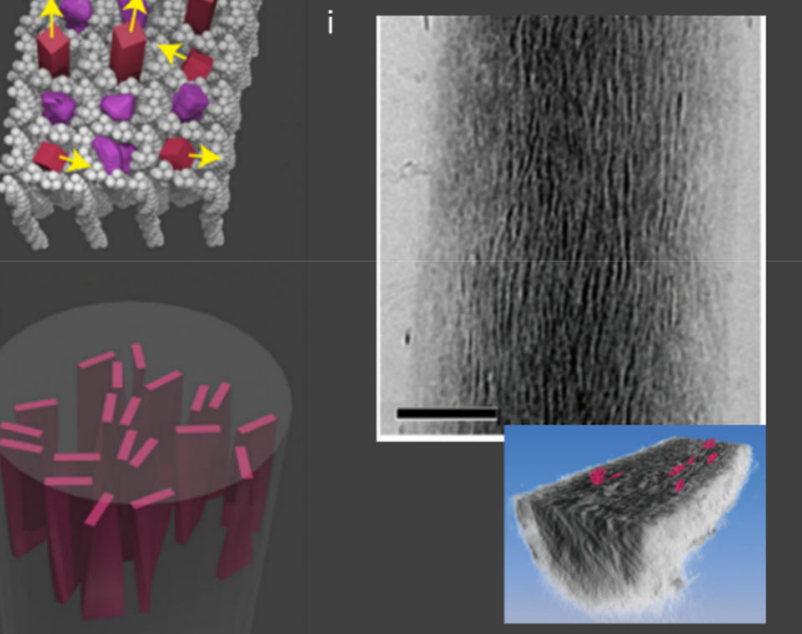

Figura 4. Mineralização das fibrilas de colágeno. A fibrila de colágeno é formada por regiões de sobreposição e lacuna que se intercalam ao longo do eixo da fibrila (a). ACP infiltra-se a partir das regiões de lacuna da fibrila (b). A ultraestrutura da fibrila de colágeno cria um ambiente confinado onde cristais de apatita são formados a partir do ACP infiltrado, dando origem à nanocristais orientados com seus eixos c paralelos ao eixo longo da fibrila de colágeno (c-g). 
caso sua solubilidade seja excedida (condição de supersaturação). A concentração de $\mathrm{Ca}^{2+}$ e $\mathrm{Pi}$ circulantes no fluido corpóreo seria suficiente para explicar a origem dos tecidos mineralizados. Porém, apesar do $\log \left(K_{p s}\right)$ para apatita em condições fisiológicas ser por volta de 30 ordens de magnitude menor que o logaritmo do produto iônico da concentração de $\mathrm{Ca}^{2+}$ e Pi no plasma humano, ${ }^{83}$ a precipitação direta de apatita ou qualquer precursor metaestável não acontece em tecidos moles saudáveis. Quando pensamos na biomineralização, partindo de uma perspectiva em que a cristalização é controlada apenas pelo $K_{p s}$ da fase mineral, nos deparamos com um paradoxo decorrente do fino controle do equilíbrio iônico do corpo humano. Por meio de mecanismos celulares muito rebuscados, nosso corpo é capaz de armazenar íons e promover a mineralização de apatita apenas em ossos e dentes, prevenindo a calcificação em tecidos moles (exceto em condições patológicas). Além disso, em certas regiões do corpo, como na adesão de tendões ao osso, a interface entre tecido mineralizado e não-mineralizado deve ser precisamente controlada de modo a manter a funcionalidade anatômica. Esse fino controle da biomineralização se dá por uma cascata de eventos espacial e temporalmente orquestrados na qual íons precursores são sistemicamente impedidos de precipitar como uma fase mineral sólida, ou são estabilizados como fases precursoras de minerais amorfos. Assim, a mineralização ocorre localmente, apenas na matriz extracelular de tecidos esqueléticos/dentários, onde o trabalho de enzimas expressas por células osteogênicas degradam os inibidores da mineralização e criam o ambiente ideal para a nucleação e crescimento da fase mineral. ${ }^{17}$

Até o momento, mostramos nesta revisão como as características da matriz extracelular (colágeno e proteínas não-colagenosas) influenciam a deposição da fase mineral. Proteínas não-colagenosas (como a osteopontina) apresentam um papel fundamental nesse processo, seja por meio dos seus grupos carregados que atuam como esponjas para a atração de íons precursores, ou por sua habilidade em estabilizar o precursor amorfo e permitir a sua infiltração nas fibrilas de colágeno. Além disso, grupos carregados existentes na fibrila de colágeno poderiam por si só atuar na nucleação da fase mineral. ${ }^{84}$ Sendo assim, características da matriz extracelular poderiam explicar a totalidade da existência de tecidos mineralizados, onde grupos carregados criam o ambiente favorável ao rompimento da barreira energética da nucleação/crescimento da fase mineral. Todavia, além da habilidade em secretar a matriz extracelular onde os cristais serão depositados, células osteogênicas devem ser capazes de criar o ambiente favorável ao controle da concentração de íons precursores, especialmente pela habilidade em remover inibidores e promover localmente a concentração de íons precursores (especialmente Pi). A mineralização é restrita a locais onde células são capazes de expressar colágeno do tipo I (a matriz) e que apresentam as enzimas capazes de remover localmente os inibidores de calcificação. ${ }^{85}$

O primeiro inibidor de calcificação identificado foi o pirofosfato (PPi) extracelular, já descrito na década de 1960 como um potente inibidor da calcificação. ${ }^{86} \mathrm{PPi}$ é um éster de fosfato formado por dois monômeros de Pi unidos por uma ligação P-O-P, e está presente no meio extracelular em concentrações da ordem de $6 \mu \mathrm{mol} / \mathrm{L}$. Este atua como inibidor de mineralização por meio da complexação com $\mathrm{Ca}^{2+}$, reduzindo as taxas de nucleação e crescimento de fosfatos de cálcio. ${ }^{87}$ Dessa forma, a manutenção de uma razão ideal Pi/PPi é universalmente aceita como uma condição necessária para a formação de mineral na matriz extracelular. ${ }^{88}$ Já foi observado in vitro, que diferentes razões $\mathrm{Pi} / \mathrm{PPi}$ promovem a formação de diferentes fases minerais. De fato, razões em torno de 140 resultam na formação exclusiva de apatitas, ao passo que a redução desta razão diminui a quantidade de apatitas formadas até valores de $\mathrm{Pi} / \mathrm{PPi}=24$, a partir do qual observa-se a formação de pirofosfato de cálcio. ${ }^{89} \mathrm{~A}$ razão $\mathrm{Pi} /$
PPi não foi completamente investigada em condições fisiológicas, porém, considerando que no meio extracelular podem ser encontrados 1-2 mmol/L de Pi e 1-10 $\mu \mathrm{mol} / \mathrm{L}$ de $\mathrm{PPi}$, a relação Pi/PPi resultante gira em torno de 1000. Conforme descrito por Garimella et al. ${ }^{90}$, uma pequena variação na ordem de $\mu \mathrm{mol}$ de PPi já é suficiente para induzir a inibição da formação de apatita, enquanto uma variação de Pi da ordem de mM é necessária para induzir a sua formação. Além de PPi ser responsável pelo ajuste fino da mineralização, fosfato também é armazenado na forma de polifosfatos $\left(-(\mathrm{Pi})_{\mathrm{n}}{ }^{\mathrm{n}}\right)$, sendo essa também uma forma de controlar a concentração de Pi livres necessários para a nucleação da fase mineral. ${ }^{91}$

Outro potente inibidor sistêmico da mineralização é a fetuína-A, uma proteína circulante com alta afinidade por $\mathrm{Ca}^{2+}$, que impede o crescimento de núcleos minerais no sangue pela mobilização desses íons e Pi em um complexo com dimensões coloidais que pode chegar a $150 \mathrm{~nm}$, conhecido por partículas de calciproteína. ${ }^{50,92}$ Uma única molécula de fetuína-A pode sequestrar até 90-120 átomos de cálcio e 54-72 íons fosfato. ${ }^{93}$ Além disso, ela é abundante no tecido ósseo, correspondendo a cerca de $25 \%$ em massa das proteínas não-colagenosas. ${ }^{94} \mathrm{O}$ processo de ossificação é acompanhado por uma intensa vascularização do tecido nascente, ${ }^{18}$ e a observação de partículas minerais oriundas da corrente sanguínea na matriz óssea em formação indica que as calciproteínas possam atuar como fonte de íons precursores para a calcificação. ${ }^{14,95,96}$

Se a nucleação da fase mineral é inibida de forma sistêmica, a existência de tecidos mineralizados indica a especialização celular a um fenótipo capaz de criar o microambiente necessário para a mineralização da matriz extracelular. Células osteogênicas, como os osteoblastos, além de possuírem papel na construção da matriz extracelular que será o alicerce para a deposição do mineral, também expressam uma série de enzimas capazes de remover localmente os inibidores da mineralização. Além disso, é crescente a ideia de que as células osteogênicas controlam a deposição da fase mineral por meio de mecanismos ainda mais rebuscados, envolvendo desde a formação intracelular de precursores minerais ${ }^{46,97,98}$ até a liberação de vesículas extracelulares mineralizantes. ${ }^{99}$

\section{VESÍCULAS DA MATRIZ DURANTE A OSSIFICAÇÃO}

As vesículas da matriz (MVs) são um tipo especial de vesículas extracelulares apontadas como as responsáveis por desencadear a formação da fase mineral na biomineralização óssea. Vesículas extracelulares são estruturas liberadas por quase qualquer tipo de célula e presentes de forma ubíqua em fluídos biológicos. Atualmente, classifica-se as vesículas extracelulares quanto à sua origem celular em duas classes: os exossomos e as microvesículas. ${ }^{100}$ Exossomos tem origem intracelular a partir de brotamentos de membranas do sistema endossomal, sendo então secretados após a fusão de corpos multivesiculares com a membrana celular, liberando assim as vesículas para o meio extracelular. Já as microvesículas são formadas a partir de brotamentos diretamente da membrana celular. As vesículas extracelulares tem despertado um grande interesse devido à sua função em transportar e direcionar diferentes cargas (por exemplo, ácidos nucléicos, lipídios e proteínas) para serem entregues e interagir com outras células, gerando uma resposta importante tanto para processos fisiológicos quanto como causa/consequência de desenvolvimentos patológicos. ${ }^{100}$ As MVs são microvesículas denominadas como "da matriz" por representarem uma classe especial de vesículas extracelulares encontradas interagindo especificamente com a matriz extracelular, e com uma função característica de induzir mineralização. ${ }^{99}$ As MVs foram pioneiramente identificadas na década de 1960 por Anderson ${ }^{101}$ e Bonucci ${ }^{102}$ que, utilizando microscopia eletrônica de transmissão, visualizaram estruturas vesiculares 
contendo mineral na matriz extracelular de células mineralizantes. As MVs fornecem um microambiente apropriado para o início da mineralização. Todos os seus componentes, proteínas e lipídios, desempenham papéis importantes neste processo, seja por catalisarem reações ou criarem interações específicas que resultam na otimização da formação da fase mineral. ${ }^{99,103}$ Além disso, são identificadas como o único tipo de vesícula extracelular capaz de se ligar a colágeno. ${ }^{104}$ Apesar dos mais de 50 anos de estudo acerca das MVs, o mecanismo pelo qual elas são secretadas e controlam a mineralização ainda permanece elusivo. Além disso, ainda são grandes os desafios para a completa compreensão do processo: identificar MVs in vivo, diferenciá-las de outras vesículas extracelulares e caracterizar com precisão a formação mineral mediada por essas estruturas in vivo e ex vivo. O rastreamento da formação mineral tem sido especialmente desafiador, principalmente devido a artefatos no preparo de amostras para microscopia eletrônica atribuídos a mecanismos de dissolução/ recristalização ou remoção de precursores metaestáveis.

MVs são isoladas a partir de tecidos biológicos por meio de protocolos de ultracentrifugação, após digestão por colagenase, que permite a obtenção de uma fração rica nessas vesículas, em detrimento de resíduos e outras vesículas extracelulares. ${ }^{105} \mathrm{~A}$ digestão por colagenase é o ponto chave na distinção das MVs de outras populações de vesículas extracelulares. A partir desse procedimento, uma população de MVs é isolada e diferenciada dos demais resíduos celulares por alguns marcadores bioquímicos, como: atividade elevada de fosfatase alcalina não-específica de tecido (TNAP); habilidade de acumular $\mathrm{Ca}^{2+}$ e $\mathrm{Pi}$ in vitro; e um perfil proteico e lipídico característico. ${ }^{99,103}$ Evidências descritas na literatura indicam que MVs atuam como nanorreatores durante a mineralização óssea devido a duas características principais: (1) seu maquinário enzimático rebuscado que opera em harmonia para controlar a relação Pi/PPi e (2) a formação da fase mineral nas MVs pode ser especificamente controlada por sua composição lipídica/ proteica. Abordaremos na próxima seção o que se sabe sobre a origem das MVs e as principiais características do seu maquinário bioquímico e membrana lipídica.

\section{BIOGENESE DAS VESÍCULAS DA MATRIZ}

As MVs possuem diâmetro que varia entre 100-300 nm e surgem por brotamento a partir da membrana plasmática de células mineralizantes, como demostrado por análises de microscopia eletrônica de ossos em formação. ${ }^{103}$ As células que secretam MVs o fazem em seus estágios finais de desenvolvimento. Em condrócitos, a biogênese das MVs coincide com a sequência de eventos que conduzem à apoptose ou morte celular programada. ${ }^{99} \mathrm{Já}$ em osteoblastos cultivados in vitro, observa-se que células estimuladas em meio osteogênico (i.e. suplementado com ácido ascórbico e alguma fonte externa de $\mathrm{Pi}$, como o beta-glicerofosfato) liberam MVs em seus estágios finais de maturação. ${ }^{106}$ Análises de composição lipídica (lipidômica) e proteica (proteômica) identificaram semelhança entre a composição das MVs e de regiões específicas da membrana celular (microvilosidades da membrana apical) ${ }^{107,108}$ sendo, portanto, comumente aceito que as MVs são liberadas por brotamento a partir de regiões específicas da membrana celular. As MVs são enriquecidas em colesterol (cerca de $30 \%$ em mol), o que pode indicar a origem dessas vesículas a partir de regiões de domínios denominados jangadas lipídicas (do inglês, lipid rafts) da membrana celular, ${ }^{108}$ cuja composição é abundante em colesterol e esfingomielinas, e confere grande afinidade para o recrutamento de proteínas ancoradas por glicosilfosfatidilinositol. ${ }^{109}$ Os fatores que levam ao brotamento das MVs, e os mecanismos intracelulares envolvidos na biogênese das MVs ainda estão pouco elucidados.

\section{VESÍCULAS DA MATRIZ: PAPEL DOS LIPÍDIOS}

A composição lipídica tem papel fundamental na modulação da atividade de enzimas presentes na membrana das MVs, ${ }^{110-116}$ porém acredita-se que o seu enriquecimento em lipídios negativamente carregados (principalmente lipídios com grupamento fosfatililserina - PS) tenha também um papel predominante na nucleação da fase mineral. A ideia de que os fosfolipídios poderiam controlar a nucleação da fase mineral derivou de estudos seminais sobre a composição da matriz óssea durante a mineralização. ${ }^{17,118}$ Observando que a maior parte dos fosfolipídios estavam intimamente associados à fase mineral nascente e que uma parcela desses lipídios só podia ser extraída após a completa desmineralização do tecido, ${ }^{119}$ foi postulado que fosfolipídios, principalmente os ácidos (como a PS), poderiam desempenhar um papel na ossificação. Cotmore at al. ${ }^{120}$ demonstraram uma interação específica entre $\mathrm{PS}$ e $\mathrm{Ca}^{2+}$ na presença de $\mathrm{Pi}$, formando um complexo PS-CaPi, sendo essa a primeira evidência a sugerir uma correlação entre fosfolipídios e estabilização das fases metaestáveis de fosfato de cálcio. Complexos lipídeo-mineral foram posteriormente extraídos de tecidos biológicos ${ }^{121,122}$ e então identificados como uma parte integral presente no interior das MVs. ${ }^{123,124}$ Atualmente sabe-se que esses complexos PS-mineral compõem o centro nucleador das MVs, identificado por MET como subunidades de $\sim 1 \mathrm{~nm}$ de diâmetro formadas por aglomerados de $\mathrm{Ca}^{2+}$ e $\mathrm{Pi}$ intimamente associados à membrana. ${ }^{125}$ Espectroscopia de absorção no infravermelho e ${ }^{31} \mathrm{P}-\mathrm{RMN}$ apoiaram a conclusão de que ACP (ou seus precursores) seja o principal componente deste centro nucleador. ${ }^{125}$ Recentemente demonstramos que a formação do centro nucleador nas MVs pode ser entendida como consequência do enriquecimento em PS na membrana interna dessas vesículas, onde nanodomínios ricos em PS são regiões específicas para aumento local de supersaturação de íons precursores, levando à nucleação de ACP na interface pela estabilização de complexos PS-CaPi. ${ }^{126}$

\section{VESÍCULAS DA MATRIZ: O MAQUINÁRIO BIOQUÍMICO}

Para uma descrição mais didática, podemos dividir as proteínas presentes nas MVs em duas categorias: (1) as responsáveis pela produção e transporte de $\mathrm{Pi}$ e (2) as responsáveis pela captação de $\mathrm{Ca}^{2+}$.

\section{(1) Com relação à homeostase de fosfato:}

(i) TNAP é uma enzima que possui atividade fosfomonohidrolítica, ou seja, produz Pi a partir da hidrólise de qualquer substrato fosforilado, como por exemplo trifosfato de adenosina (ATP), difosfato de adenosina (ADP), glicose-1-fosfato, glicose-6-fosfato, gliceraldeídofosfato, entre outros. ${ }^{127}$ De maneira mais eficiente e seletiva, converte PPi em duas moléculas de Pi, ou uma molécula de ATP em Pi e ADP. A existência de uma enzima com atividade fosfomonohidrolítica, capaz de produzir Pi localmente durante a ossificação, foi proposta na década de $1920,{ }^{36}$ sendo posteriormente identificada e isolada. ${ }^{128} \mathrm{~A}$ TNAP pertence a uma família de proteínas com diferentes isoformas dessa enzima estão distribuídas em quase todos os tecidos. Em humanos, as fosfatases alcalinas são codificadas por quatro genes tradicionalmente nomeados referindo-se aos tecidos onde são predominantemente expressos. ${ }^{129} \mathrm{~A}$ fosfatase alcalina não-específica de tecido (TNAP) é codificada pelo gene $A L P L \mathrm{e}$ expressa em maiores níveis no fígado, ossos e rim, sendo por essa razão chamada de não-específica de tecido. As outras três isoformas são tecido-específicas: a fosfatase alcalina placentária (PLAP, gene $A L P P$ ), de células germinativas (GCAP, gene $A L P P 2$ ) e intestinal (IAP, gene $A L P I$ ). Independentemente de sua origem, as fosfatases alcalinas são enzimas constituída por duas subunidades idênticas com 
massa molecular de aproximadamente $60 \mathrm{kDa}$, contendo em cada sítio catalítico três íons metálicos (dois $\mathrm{Zn}^{2+} \mathrm{e} \mathrm{um} \mathrm{Mg}^{2+}$ ), necessários para a atividade da enzima. ${ }^{130}$ Um novo sítio não-catalítico que parece ser ocupado por $\mathrm{Ca}^{2+}$ foi descoberto após a resolução da estrutura tridimensional da PLAP. ${ }^{131,132}$ A importância estrutural e funcional deste novo sítio metálico confirma estudos anteriores que indicavam que, em cartilagem, a fosfatase alcalina é uma glicoproteína ligante de $\mathrm{Ca}^{2+} .{ }^{133}$ Desde sua identificação, a TNAP tem sido apontada como uma das principais enzimas responsáveis pela calcificação da matriz óssea. ${ }^{88}$ Apesar da presença de fosfatases alcalinas em diversos tecidos no corpo, a mineralização é fisiologicamente restrita à cartilagem e ao osso, uma vez que requer uma matriz extracelular de composição específica (colágeno) como molde para a deposição de mineral, e a expressão conjunta de TNAP e colágenos fibrilares ocorrem apenas em zonas de formação óssea ${ }^{85}$ Interessantemente, muitas condições patológicas que resultam em mineralização extracelular de tecidos moles envolve a ativação da TNAP. ${ }^{134}$

A TNAP é encontrada na superfície da membrana de células osteogênicas e na membrana das MVs, de forma que a sua expressão é um marcador da diferenciação celular para um fenótipo mineralizante. Além disso, níveis elevados de TNAP têm sido encontrados em MVs, atestando o papel dessa enzima na remoção de PPi e geração local de Pi para induzir a mineralização. Camundongos deficientes em TNAP produzem MVs também carentes em TNAP. ${ }^{135}$ Análises in vivo da matriz óssea nesses animais mostram regiões com mineralização deficiente ao redor das MVs, devido à falha na função de gerar Pi localmente para a propagação da mineralização. ${ }^{104}$ Além da geração local de Pi, a TNAP pode também estar envolvida na remoção de grupos fosfato de algumas proteínas, ${ }^{136,137}$ como a osteopontina, sendo capaz de modificar seu nível de fosforilação e por consequência, afetando seu poder inibitório durante a calcificação. ${ }^{137,138} \mathrm{~A}$ habilidade da TNAP em controlar localmente o nível de fosforilação de proteínas não-colagenosas impõe um novo nível de regulação da calcificação. ${ }^{17}$

A importância da TNAP no controle da biomineralização é ainda evidenciada por doenças relacionadas à falha na expressão dessa enzima, como a hipofosfatasia (HPP), que é uma doença óssea hereditária. ${ }^{139} \mathrm{~A}$ fisiopatologia da HPP se deve basicamente a falhas da mineralização de tecidos duros, o que leva ao raquitismo ou osteomalácia, bem como a malformações dentárias. Além disso, a mineralização reduzida das costelas resulta em insuficiência respiratória grave, que é a principal causa de morte. A HPP é hereditária e recessiva, mas casos autossômicos dominantes foram relatados nas formas mais leves. Até o momento, um total de 335 mutações espalhados por todo o gene $A L P L$ foram relatadas ${ }^{139}$. No entanto, a terapia de reposição enzimática com TNAP (sALP-FcD10, também conhecido como ENB-0040 ou asfotase alfa) direcionada a minerais mostrou resultados promissores e abriu um novo panorama no tratamento dessa doença, até então intratável. ${ }^{140,141}$

(ii) A nucleosídeo pirofosfatase/fosfodiesterase 1 (NPP1) pertence a uma classe de enzimas (NPPs) expressas em diversos tecidos tais como ósseo, cartilaginoso e adiposo, possuindo funções específicas em cada tipo tecidual/celular. Dentre as principais enzimas dessa grande família, destaca-se a NPP1 (ou PC-1), que é uma proteína integral de membrana, ${ }^{142,143} \mathrm{com}$ peso molecular de aproximadamente $125 \mathrm{kDa}$ e um total de 906 resíduos de aminoácidos. Esta enzima se destaca por sua capacidade de hidrolisar diversos tipos de nucleotídeos polifosforilados e de fosfodiésteres para a geração de PPi. ${ }^{144}$ Desta forma, a NPP1, como a grande geradora de PPi, juntamente com a TNAP, que controla a razão Pi/PPi no meio extracelular, possuem, juntas, funções cruciais na produção e regulação das concentrações de Pi na região extracelular das MVs, influenciando diretamente a geração da fase mineral. ${ }^{145}$ Falhas na expressão de NPP1 resultam em anormalidades relacionadas à hipermineralização óssea e mineralização patológica de tecidos moles, incluindo calcificação arterial. ${ }^{146}$ Em contrapartida, a expressão elevada de NPP1 resulta na calcificação de tecidos cartilaginosos, devido à formação de pirofosfato de cálcio diidratado (CPPD), o que ocorre principalmente durante o processo de envelhecimento da cartilagem do menisco do joelho. ${ }^{147,148}$ A propósito, assim como em tecidos que expressam excesso de NPP1, a precipitação anormal de CPPD também tem sido observada em associação com a deficiência de TNAP. ${ }^{146}$

(iii) A PHOSPHO1 é uma fosfomonohidrolase encontrada no interior das MVs. ${ }^{149}$ Estudos de localização utilizando-se anticorpos mostraram que a PHOSPHO1 é especificamente localizada em regiões mineralizantes do tecido esquelético. ${ }^{150}$ Juntamente com a TNAP, ela é considerada como uma das principais enzimas produtoras de Pi durante a biomineralização, levando ao acúmulo de Pi no interior das MVs. Animais duplamente deficientes em TNAP e PHOSPHO1 exibiram ablação completa de mineralização esquelética e letalidade perinatal. ${ }^{151}$ Apesar das evidências concretas do papel da PHOSPHO1 na ossificação, a via bioquímica pela qual essa enzima ajuda na concentração de Pi no interior das MVs permanece obscura. A PHOSPHO1 gera Pi através da hidrólise de dois substratos: fosfocolina (PC) e fosfoetanolamina (PE). Diferentes vias têm sido propostas para a produção local desses substratos, seja pela ação da fosfolipase $\mathrm{PLA}_{2}$, da ectonucleotídeo pirofosfatase/fosfodiesterase 6 (NPP6) ou de esfingomielinases (SMPD3), como recentemente revisados. ${ }^{152}$ Camundongos deficientes em PHOSPHO1 apresentaram, além de ossificação comprometida, um número reduzido de MVs, indicando que essa enzima possa também estar envolvida na biogênese das vesículas. ${ }^{146}$

(iv) Transportadores de fosfato PiT-1 (SLC20A1) e PiT-2 (SLC20A2) também chamados de cotransportadores $\mathrm{Na}^{+} / \mathrm{Pi}$ do tipo III são encontrados nas MVs. ${ }^{153}$ PiT-1 e PiT-2 foram propostos como proteínas capazes de intermediar o carregamento de Pi extracelular para o interior das MVs. ${ }^{146} \mathrm{O}$ PiT-1 foi encontrado em condrócitos hipertróficos durante ossificação endocondral em camundongos, ${ }^{154}$ evidenciando seu importante papel na regulação das concentrações de Pi em ossos e cartilagens. Além disso, foi demonstrado que Pi modula a diferenciação de condrócitos e osteoblastos. ${ }^{155}$ Sugita $e t$ $a l .{ }^{156}$ sugeriu que a síntese de ATP mediada pelo transporte de Pi para o interior das céulas via PiT-1 é fundamental para a regulação da apoptose e mineralização de condrócitos. Lau et al. ${ }^{157}$ demonstraram que a atividade de co-transporte $\mathrm{Na}^{+} / \mathrm{Pi}$ através de PiT-1 está associada com a diferenciação de osteoblastos e que o aumento da concentração de Pi extracelular afeta a diferenciação de condrócitos. Suzuki et al. ${ }^{158}$ também investigaram os efeitos de superexpressão de PiT-1 transgênica na razão $\mathrm{Ca}^{2+} / \mathrm{Pi}$ e metabolismo ósseo. Ratos transgênicos PiT-1 exibiram metabolismo mineral anormal e também redução da atividade da TNAP nos osteoblastos, embora a mineralização da matriz óssea e o desenvolvimento esquelético fossem normais. ${ }^{159}$ Ratos adultos transgênicos PiT-1 exibiram hiperfosfatemia, associada a redução da massa óssea. ${ }^{159}$ Neste estudo in vitro, a superexpressão de PiT-1 em osteoblastos levou a aumento acentuado no transporte de Pi e regulação negativa da expressão da TNAP.

(v) Finalmente uma Na,K-ATPase (NKA) também é encontrada em membrana de $\mathrm{MV},{ }^{160}$ o que pode promover a mineralização por aumentar a concentração local de Pi e consequentemente alterando as razões Pi/PPi. NKA é um transportador catiônico ativo encontrado na membrana celular de todos os mamíferos, atuando no movimento de três $\mathrm{Na}^{+}$para fora e dois $\mathrm{K}^{+}$para dentro das células, para cada molécula de ATP hidrolisada. ${ }^{161}$ A estrutura funcional da 
enzima é um heterodímero formado por duas subunidades alfa $(\alpha)$ e beta $(\beta)$ principais. A subunidade $\alpha(110 \mathrm{kDa})$ tem dez segmentos transmembrana e três domínios citoplasmáticos, enquanto a subunidade $\beta(55 \mathrm{kDa})$ tem apenas um segmento transmembrana e uma porção extracelular altamente glicosilada. ${ }^{162,163}$ Existem 4 isoformas para as subunidades $\alpha$ e $\beta$ que podem associar-se em dímeros de atividade e inibição enzimática características. A presença das isoformas $\alpha 1, \alpha 2, \beta 1$ e $\beta 2$ foram identificadas em condrócitos isolados de articulação cartilaginosa de bovinos ${ }^{164} \mathrm{e}$ em MVs isoladas de condrócitos hipertróficos de fêmures de embriões de frango. ${ }^{165,166} \mathrm{O}$ fato de que nas membranas de MVs possa haver uma forma dimérica da NKA aliado às evidências de que osteoblastos são capazes de mineralizar a partir da hidrólise de ATP, ${ }^{167}$ podem evidenciar um papel importante desta enzima na biomineralização. Experimentos in vitro em andamento em nosso laboratório confirmam que a NKA poderia também atuar na produção de Pi para auxiliar na mineralização.

\section{(2) Proteínas responsáveis pela captação de cálcio}

Evidências experimentais sugeriram que anexinas, como proteínas de ligação a $\mathrm{Ca}^{2+}$ e a fosfolipídios, estão envolvidas na homeostase de cálcio das células mineralizantes e no influxo de $\mathrm{Ca}^{2+}$ para as MVs. ${ }^{168,169}$ Três proteínas da família das anexinas (AnxA2, AnxA5 e AnxA6) estão presentes nas MVs, e apesar de não apresentarem domínios peptídicos característicos de proteínas transmembranas, podem ser responsáveis pela captação de $\mathrm{Ca}^{2+}$ e levar para o interior das vesículas. ${ }^{103,170}$ Dentre essas anexinas, a AnxA5, especificamente, é uma proteína de $\sim 35 \mathrm{kDa}$, responsável pela formação de canais de $\mathrm{Ca}^{2+}$ pela associação de subunidades desta proteína tanto com a face externa quanto interna da membrana das MVs. ${ }^{171}$ A AnxA5 humana foi a primeira a ter sua estrutura tridimensional caracterizada, a qual revela uma molécula ligeiramente curva, constituída por quatro repetições homólogas constituídas por cerca de 70 aminoácidos, formando domínios compactos de $5 \alpha$-hélices. ${ }^{172}$ Estes domínios estão dispostos de modo a formar um poro hidrofílico no centro da proteína e esse poro pode apresentar função de canal de $\mathrm{Ca}^{2+}$ na membrana das MVs. ${ }^{173} \mathrm{~A}$ função de canal iônico foi reproduzida em membranas reconstituídas in vitro de maneira semelhante à descrita para as MVs. ${ }^{171}$ Adições de anticorpo anti-anexina específico ou de inibidor de canal de anexina K-201 ${ }^{174}$ levou à diminuição do acúmulo de $\mathrm{Ca}^{2+}$ e redução da capacidade de mineralização das MVs. ${ }^{175,176}$ Além disso, a adição de anexinas exógenas (AnxA2, AnxA5 e AnxA6) a vesículas que não continham anexinas e que não mineralizavam, foi capaz de restaurar a sua capacidade de acumular $\mathrm{Ca}^{2+}$. Bolean et al ${ }^{177}$ mostraram que proteolipossomos contendo AnxA5 exibiram alta afinidade de ligação a fibrilas de colágeno tipo II, o que indica um possível papel desta proteína na ligação de MVs à matriz orgânica durante a mineralização. A afinidade de anexinas por sítios específicos de ligação na fibrila de colágeno tem sido relatada na literatura. ${ }^{178}$

Outro membro da família das anexinas encontrado nas MVs é a AnxA6, com $\sim 68 \mathrm{kDa}$. Análises bioquímicas revelaram que a AnxA6 está presente em três regiões distintas nas MVs: (a) ligada à parte externa da membrana, na presença de $\mathrm{Ca}^{2+}$; (b) localizada na superfície interna da monocamada das membranas e (c) inserida na bicamada hidrofóbica e co-localizada com regiões ricas em Chol. ${ }^{179}$ De maneira distinta dos demais membros da família das anexinas, que são estruturalmente caracterizados pela presença de um núcleo altamente conservado composto por quatro domínios homólogos, ${ }^{180}$ a AnxA6 possui oito domínios em seu núcleo. ${ }^{181}$

Um trabalho recente de Veschi et al. ${ }^{179}$ sugeriu um possível mecanismo de translocação de AnxA6 através da membrana das MVs. Em uma etapa inicial, as anexinas no lúmen de MVs ligam-se à fosfatidilserina (PS), presente na lamela interna da bicamada das MVs, de modo dependente de $\mathrm{Ca}^{2+}$, o que desencadeia a formação de um centro nucleador com o auxílio de AnxA5 e outras proteínas. ${ }^{182}$ A AnxA6 também pode contribuir para o acúmulo de $\mathrm{Ca}^{2+}$ criando ambiente favorável para a formação de apatita. Na etapa seguintes, uma redução local do $\mathrm{pH}$ durante a formação de apatita, pode promover a inserção de AnxA6 na bicamada das MVs, o que torna a AnxA6 resistente à extração por EGTA. ${ }^{183} \mathrm{~A}$ inserção de AnxA6 na membrana induzida por $\mathrm{pH}$ ligeiramente ácido é aparentemente revertida pelo aumento do $\mathrm{pH} .{ }^{184}$ Este fato sugere que AnxA6 poderia ser expelida na matriz extracelular, onde o $\mathrm{pH}$ é neutro, ou também poderia se ligar a PC presente na superfície das MVs, Assim, a AnxA6, bem como a AnxA5, poderia contribuir para reforçar as interações das MVs com as fibras de colágeno. ${ }^{177,179}$ Essas diferentes localizações e formas de interação na membrana das MVs indicam que a AnxA6 pode exercer funções distintas durante o processo de mineralização, entretanto até o momento essas funções não estão bem elucidadas. Ainda, a capacidade da AnxA6 de transportar $\mathrm{Ca}^{2+}$, como descrito para AnxA5, ainda não foi descrita. ${ }^{170,171}$

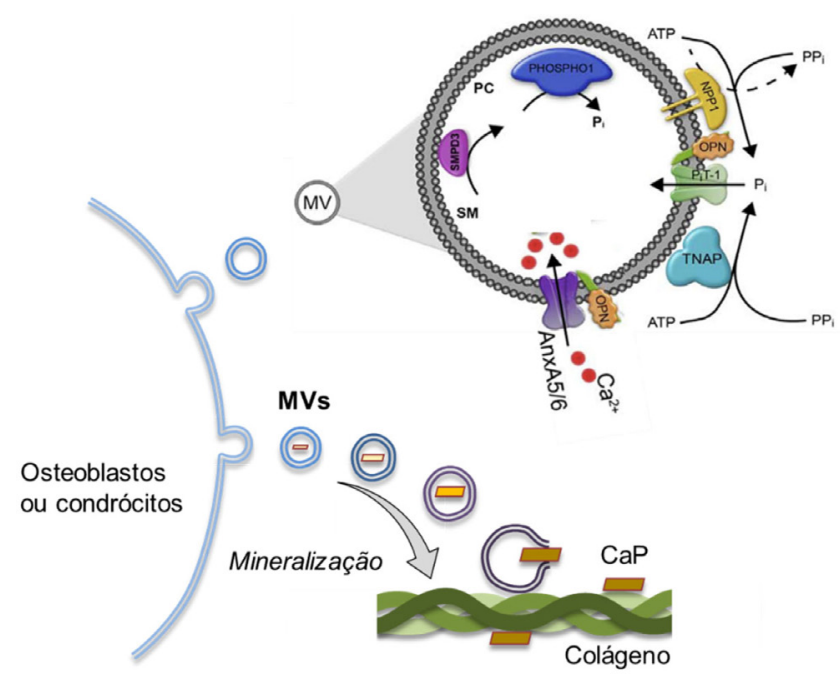

Figura 5. Representação esquemática do maquinário bioquímico das MVs. Diferentes enzimas e proteínas atuam em harmonia de modo a controlar localmente a razão Pi/PPi, assim como acumular Pi e $\mathrm{Ca}^{2+}$ necessários para a mineralização das fibrilas de colágeno. MVs acumulam $\mathrm{Ca}^{2+} e \mathrm{Pi}$ no seu lúmen, dando origem à uma fase mineral de razão Ca/P $\sim 1,0$, típico da formação de uma fase amorfa e desordenada. ${ }^{185} \mathrm{O}$ mecanismo pelo qual as MVs poderiam mediar a mineralização de fibrilas de colágeno a partir desta fase precursora ainda permanece carente de detalhamento, no entanto, alguns cenários podem ser especulados: (1) as vesículas contendo ACP poderiam se infiltrar diretamente na matriz de colágeno e liberar seu conteúdo, por efeito mecânico ou por ação de enzimas específicas ${ }^{186}$ (2) a fase precursora liberada pelas MVs poderia interagir com proteínas não-colagenosas (como a osteopontina), que controlariam a infiltração da fase precursora no interior das fibrilas de colágeno. Imagem adaptada da referência. ${ }^{99}$

\section{VESÍCULAS DA MATRIZ: MODELOS MIMÉTICOS}

A complexidade funcional, estrutural e composicional das MVs impõe aos pesquisadores a utilização de modelos simplificados que sejam capazes de mimetizar parcialmente sua composição, morfologia e estrutura, a fim de se explorar as funções específicas dos seus constituintes. Lipídios de membrana, que são intrinsicamente insolúveis em meio aquoso na sua forma monomérica, se auto-organizam espontaneamente de modo a formar partículas multilamelares em meio aquoso. Para formar vesículas unilamelares (i.e., vesículas contendo uma única bicamada concêntrica, semelhante às membranas naturais), as vesículas multilamelares podem ser sonicadas 
ou extrusadas até atingirem dimensões manométricas. ${ }^{187}$ Essas vesículas unilamelares são comumente chamadas de lipossomos. Em nosso grupo, propomos uma abordagem biomimética com o uso de proteolipossomos para reconstruir in vitro a função de diferentes enzimas/proteínas presentes nas MVs. Proteolipossomos lipossomos nos quais proteínas são incorporadas de modo a reconstituir in vitro suas funcionalidades. ${ }^{188}$ Essas vesículas sintéticas criam um modelo biomimético capaz de imitar a estrutura organizacional e a função das biomembranas, tornando essas estruturas um modelo experimental vantajoso e conveniente para ajudar no avanço da compreensão da calcificação mediada por MVs..$^{99,187}$ Os proteolipossomos são fáceis de preparar e podem ser fabricados usando diferentes métodos, com um fino controle da composição lipídica e proteica da membrana e dos eletrólitos presentes, representando assim um modelo experimental conveniente para reproduzir algumas características essenciais do processo de biomineralização.

Uma das enzimas que temos dedicado atenção especial quanto à sua reconstituição em proteolipossomos é a TNAP. Como estabelecido por nosso grupo, uma vez isolada, a TNAP pode ser subsequentemente reconstituída na bicamada lipídica de lipossomos pelo uso da âncora de glicofosfatidilinositol (GPI) da enzima. ${ }^{110,144} \mathrm{Um}$ ponto relevante a ser observado é que a enzima ligada a lipossomos mantém a capacidade de hidrolisar diferentes substratos, tais como ATP, ADP, AMP, PPi e p-nitrofenilfosfato. ${ }^{144,189} \mathrm{O}$ microambiente experimentado por uma enzima reconstituída em membrana mimetiza a interação com lipídios, acesso à substratos, inibidores e moduladores de uma maneira mais fisiológica do que em solução. Os proteolipossomos contendo TNAP possuem tamanho na faixa de 100 a $200 \mathrm{~nm},{ }^{113,189}$ comparável ao tamanho médio de uma MV nativa. ${ }^{126}$ Imagens obtidas por MET mostraram que a reconstituição da enzima não afetou a morfologia dos lipossomos. ${ }^{144}$ Garcia et al. ${ }^{190}$ demonstraram que a porção proteica da TNAP está provavelmente próxima da superfície da membrana, sugerindo que a modulação da atividade da TNAP pode estar relacionada com a proximidade e a composição lipídica das vesículas. De fato, Bolean et al. ${ }^{113}$ e Favarin et al. ${ }^{112,189}$ demonstraram que as propriedades catalíticas da TNAP variam dependendo do microambiente lipídico onde a enzima se encontra. Estudos que combinaram os fosfolipídios 1,2-dipalmitoil-sn-glicero-3fosfocolina (DPPC) e 1,2-dioleoil-sn-glicero-3-fosfocolina (DOPC), associados ou não a diferentes esteróis, mostraram maior afinidade da TNAP pela monocamada lipídica saturada, refletida na sua maior incorporação nos lipossomos. ${ }^{12,189}$ Além disso, proteolipossomos compostos por DPPC:Chol propagaram a deposição de mineral mais eficientemente quando comparados com a composição DOPC:Chol, mostrando que a mobilidade e o grau de empacotamento lipídico são chave para que o processo de deposição de fosfato de cálcio ocorra apropriadamente. ${ }^{12,189}$ Ensaios de mineralização in vitro demostraram que proteolipossomos contendo TNAP são capazes de induzir a mineralização in vitro mesmo na ausência de nucleadores, mostrando que o microambiente lipídico é essencial para a indução e propagação do mineral fosfato. ${ }^{109}$ Esse processo é ainda controlado pela presença de esteróis na composição dos proteolipossomos, mostrando a importância da fluidez da membrana lipídica também na propagação do mineral. ${ }^{112}$

Proteolipossomos construídos por lipídios presentes nos lipid rafts, como Chol, SM e gangliosídeo GM1 (lipídeo comumente encontrado nestes domínios com muita afinidade para Chol), nos quais as MVs são enriquecidas, foram utilizados na investigação de interações com TNAP. A análise calorimétrica dos lipossomos e proteolipossomos indicou segregação lateral de fase somente em presença de Chol, com a formação de microdomínios ricos neste lipídeo. ${ }^{112-114,189} \mathrm{O}$ aumento gradual na complexidade das vesículas diminuiu a atividade da TNAP incorporada, e a presença da enzima também alterou a temperatura de transição de fase dos lipídios nas vesículas. ${ }^{113,114}$ Esses estudos mostram a versatilidade dos proteolipossomos como modelos miméticos, por meio dos quais podese inferir sobre aspectos funcionais da TNAP, além de parâmetros que favorecem à sua incorporação na membrana. Associadas às características biofísicas da membrana (fluidez e presença de microdomínios, por exemplo), esses modelos consistem ainda de importante ferramenta para a compreensão da biogênese das MVs.

Além da TNAP, outras proteínas importantes no processo de biomineralização mediada por MVs tem sido estudada com o uso de proteolipossomos, como a NKA ${ }^{191}$ e a NPP1. ${ }^{144}$ Simão et al. ${ }^{144}$ descreveram a produção e caracterização de proteolipossomos contendo além de TNAP, a enzima NPP1, mostrando a inter-relação entre essas enzimas na utilização de substratos fisiológicos como um meio de compreender a interação mais complexa dessas enzimas em MVs. Os estudos de reconstituição de função de enzimas relevantes ao processo de biomineralização foram posteriormente validados com uso de MVs nativas, ${ }^{135}$ demonstrando que tanto a cooperatividade quanto a competição entre diferentes enzimas reguladoras de $\mathrm{Pi}$ (TNAP, NPP1 e PHOSPHO1) fornecem um nível adicional de regulação do fluxo de metabólitos para o controle do processo de mineralização.

Por fim, outra classe de proteína que tem sido explorada na reconstituição em proteolipossomos são as anexinas. ${ }^{170,177,179,192} \mathrm{~A}$ associação entre AnxA5 e TNAP foi estudada em proteolipossomos formados por DPPC e DPPS, de modo a determinar se a presença de AnxA5 afeta os parâmetros cinéticos da TNAP. A melhor eficiência catalítica foi obtida em proteolipossomos de DPPC:DPPS contendo AnxA5, condições que aumentaram a especificidade da hidrólise de PPi pela TNAP, quando comparada à hidrólise de ATP. ${ }^{170}$ Além disso, AnxA5 foi capaz de mediar o influxo de $\mathrm{Ca}^{2+}$ em proteolipossomos de DPPC puro e DPPC:DPPS, em concentrações fisiológicas de $\mathrm{Ca}^{2+}(\sim 2 \mathrm{mM})$, processo esse que não foi afetado pela presença de TNAP. ${ }^{170}$ Estes resultados atestaram que o sinergismo entre diferentes componentes das MVs pode ser mimetizado com o uso de proteolipossomos de modo a delinear fatores que otimizam a função de proteínas.

Estudos topográficos de vesículas lipídicas por microscopia de força atômica (AFM), em modo contato intermitente, possibilitam a visualização de mudanças estruturais ocasionadas por alterações na fluidez da membrana, que resultaram na formação de domínios lateralmente segregados na presença das proteínas AnxA5, TNAP ${ }^{192}$ e AnxA6. ${ }^{179}$ Imagens de contraste de fase, revelaram a presença de protrusões com propriedades visco-elásticas distintas, sugerindo que a presença das proteínas induz alterações locais na fluidez da membrana. Domínios mais complexos foram observados quando ambas as proteínas, TNAP e AnxA5, estavam presentes nas vesículas, destacando a importância da AFM na caracterização dos modelos miméticos de MVs. ${ }^{192}$ Tais proteolipossomos foram capazes de se ligar a matrizes de colágeno, porém com afinidade reduzida em presença de TNAP, mimetizando a função das MVs no momento de ancoragem à matriz extracelular colagenosa. ${ }^{177,195}$

Proteolipossomos também são úteis para estudos funcionais decorrentes de alterações estruturais de proteínas. Mutações na TNAP associadas a doenças, como as encontradas na HPP, ${ }^{193}$ podem ser minunciosamente estudadas quando presente em sistemas-modelo vesiculares que imitam apropriadamente o ambiente biológico in vivo da enzima. Considerando que as vesículas artificiais mimetizam adequadamente o comportamento cinético de enzimas no ambiente de MVs naturais, estas podem ser usadas para a triagem de pequenos compostos moleculares capazes de modular a atividade de enzimas com potencial terapêutico. ${ }^{194-197}$ Desta forma, ressalta-se a importância da elucidação de interações moleculares referentes às propriedades 
físicas, organização lateral de fase, propriedades cinéticas de enzimas e interações lipídeo-lipídeo, lipídeo-proteína e proteína-proteína para a modulação da deposição de mineral. Proteolipossomos como modelos biomiméticos de MVs contendo composições lipídicas e proteicas variadas certamente ajudarão a elucidar interações ainda mais específicas em estudos posteriores, desvendando os mecanismos complexos envolvidos nos processos de mineralização fisiológicos e patológicos.

De maneira complementar, monocamadas de Langmuir e Filmes de Langmuir-Blodgett (LB) podem ser utilizados como modelos miméticos de MVs. Apesar de não mimetizarem a geometria dessas vesículas, os filmes de Langmuir são úteis para determinação de parâmetros termodinâmicos de interação lipídeo-lipídeo e lipídeoproteína, como energia livre e área de excesso, pressão de exclusão e fatores de compressibilidade isotérmicos. ${ }^{198}$ Ainda, fatores que regulem a atividade de enzimas importantes para o processo de mineralização relacionados à composição das monocamadas, e também investigação da composição da fase mineral, podem ser investigados com técnicas acopladas à cuba de Langmuir. Recentemente, nosso grupo desenvolveu metodologia para acompanhar de maneira simultânea a inserção de TNAP em monocamadas contendo DPPC e Chol e mudanças na atividade da enzima. ${ }^{199}$ Para isso, um espectrofotômetro UV-Vis portátil operado por fibra óptica foi acoplado ao um equipamento de tensão superficial dinâmica pelo método da gota pendente. Aumento na atividade da enzima foi observado com aumento do empacotamento lipídico na interface líquido-ar. ${ }^{199}$ Utilizando-se cuba de Langmuir, filmes LB compostos por ácido dimiristoilfosfatítico (DMPA) e TNAP foram transferidos para suportes de titânio. ${ }^{200} \mathrm{~A}$ atividade da enzima foi mantida nesses filmes, que foram capazes de propagar mineralização de apatita e representam uma alternativa de recobrimentos biomiméticos para implantes. ${ }^{200}$ Derradi et al. ${ }^{111}$ utilizaram monocamadas de Langmuir contendo DPPC e Chol para estudos da modulação da atividade enzimática da TNAP. Recentemente, Cruz et al. acompanharam a mineralização in situ a partir de monocamadas de Langmuir contendo DPPC e DPPC:DPPS, utilizando-se espectroscopia de infravermelho acoplada à cuba de Langmuir (PM-IRRAS). ${ }^{126} \mathrm{~A}$ fase mineral foi caracterizada após transferência a suportes sólidos por MET e FTIR. Resultados comparáveis à mineralização de monocamadas compostas por lipídios isolados de MVs nativas foram obtidos apenas em presença de DPPS, evidenciando a papel primordial deste lipídeo na indução de mineralização.

\section{PERSPECTIVAS}

A formação de tecidos mineralizados é um processo rebuscado que envolve uma série de eventos celulares temporal e espacialmente regulados para construir a matriz extracelular e controlar a deposição da fase mineral. Fibrilas de colágeno mineralizadas são o bloco construtor da matriz óssea/dentária, que se auto-organiza de forma multiescalar, gerando um material compósito de hierarquia e propriedades únicas. Um dos grandes desafios atuais da ciência de materiais é sintetizar, in vitro, materiais que reproduzam com fidelidade a estrutura e composição da matriz mineralizada. ${ }^{201,202}$ Todavia, a compreensão em detalhes desses processos é uma ferramenta primordial para a translação da ciência básica à aplicação tecnológica. MVs nativas e proteolipossomos podem ser potencialmente utilizados como agentes terapêuticos em patologias relacionadas à perda óssea. ${ }^{203} \mathrm{~A}$ habilidade inerente desses materiais de controlar a deposição da fase mineral em diferentes níveis pode superar limitações e riscos associados às abordagens de terapia celular. Desta forma, a caracterização do processo de comunicação mediada por vesículas no microambiente ósseo pode fornecer informações relativas à complexidade do desenvolvimento e manutenção óssea. Assim, estudos futuros sobre a biogênese, absorção e composição de MVs, poderão desvelar biomarcadores e auxiliar no desenvolvimento de novos materiais osteoindutores e osteocondutores, regeneradores ou aceleradores do processo de biomineralização. A compreensão dos mecanismos moleculares que levam à biomineralização poderão ainda resultar em materiais para tratamento de uma ampla variedade de patologias relacionadas a mineralização ectópica.

\section{AGRADECIMENTOS}

Este trabalho foi financiado pelos projetos: Fundação de Amparo à Pesquisa do Estado de São Paulo (FAPESP, 2017/20846-2; 2019/08568-2; 2019/25054-2); Coordenação de Aperfeiçoamento de Pessoal de Nível Superior (CAPES, Finance Code 001, 1738449 , 88887.320304/2019-00,) e Conselho Nacional de Desenvolvimento Científico e Tecnológico (CNPq, 304021/2017-2). PC and APR são pesquisadores do CNPq.

\section{REFERÊNCIAS}

1. Mann, S.; Nature 1993, 365, 499.

2. Meldrum, F. C.; Cölfen, H.; Chem. Rev. 2008, 108, 4332.

3. Dorozhkin, S. V.; Prog. Biomater. 2016, 5, 9.

4. Lacruz, R. S.; Habelitz, S.; Wright, J. T.; Paine, M. L.; Physiol. Rev. 2017, 97, 939.

5. Weiner, S.; Wagner, H. D.; Annu. Rev. Mater. Sci. 1998, 28, 271.

6. Robinson, R. A.; Watson, M. L.; Anat. Rec. 1952, 114, 383.

7. Xu, Y.; Nudelman, F.; Eren, E. D.; Wirix, M. J. M.; Cantaert, B.; Nijhuis, W. H.; Hermida-Merino, D.; Portale, G.; Bomans, P. H. H.; Ottmann, C.; Friedrich, H.; Bras, W.; Akiva, A.; Orgel, J. P. R. O.; Meldrum, F. C.; Sommerdijk, N.; Nat. Commun. 2020, 11, 5068.

8. Meldrum, F. C.; Cölfen, H.; Chem. Rev. 2008, 108, 4332.

9. Gebauer, D.; Wolf, S. E.; J. Am. Chem. Soc. 2019, 141, 4490.

10. De Yoreo, J. J.; Gilbert, P. U. P. A.; Sommerdijk, N. A. J. M.; Penn, R. L.; Whitelam, S.; Joester, D.; Zhang, H.; Rimer, J. D.; Navrotsky, A.; Banfield, J. F.; Wallace, A. F.; Michel, F. M.; Meldrum, F. C.; Colfen, H.; Dove, P. M.; Science (80-. ). 2015, 349, aaa6760.

11. Cölfen, H.; Mann, S.; Angew. Chem. Int. Ed. Engl. 2003, 42, 2350.

12. Gower, L. B.; Chem. Rev. 2008, 108, 4551.

13. Mahamid, J.; Addadi, L.; Weiner, S.; Cells Tissues Organs 2011, 194, 92.

14. Haimov, H.; Shimoni, E.; Brumfeld, V.; Shemesh, M.; Varsano, N.; Addadi, L.; Weiner, S.; Bone 2020, 130, 115086.

15. Crane, N. J.; Popescu, V.; Morris, M. D.; Steenhuis, P.; Ignelzi, M. A.; Bone 2006, 39, 434.

16. Habraken, W. J. E. M.; Tao, J.; Brylka, L. J.; Friedrich, H.; Bertinetti, L.; Schenk, A. S.; Verch, A.; Dmitrovic, V.; Bomans, P. H. H.; Frederik, P. M.; Laven, J.; van der Schoot, P.; Aichmayer, B.; de With, G.; DeYoreo, J. J.; Sommerdijk, N. A. J. M.; Nat. Commun. 2013, 4, 1507.

17. Reznikov, N.; Hoac, B.; Buss, D. J.; Addison, W. N.; Barros, N. M. T.; McKee, M. D.; Bone 2020, 138, 115447.

18. Hartmann, C.; Yang, Y.; In Principles of Bone Biology; Elsevier, 2020; pp. 5-44.

19. Robling, A. G.; Bonewald, L. F.; Annu. Rev. Physiol. 2020, 82, 485.

20. Xu, F.; Teitelbaum, S. L.; Bone Res. 2013, 1, 11.

21. Del Fattore, A.; Cappariello, A.; Teti, A.; Bone 2008, 42, 19.

22. Sivaraj, K. K.; Adams, R. H.; Dev. 2016, 143, 2706.

23. Hannah, S. S.; McFadden, S.; McNeilly, A.; McClean, C.; J. Cell. Physiol. 2021, 236, 721 .

24. Srinivas, V.; Bohensky, J.; Zahm, A. M.; Shapiro, I. M.; Cell Cycle 2009, 8,391 .

25. Reznikov, N.; Shahar, R.; Weiner, S.; Acta Biomater. 2014, 10, 3815. 
26. Shapiro, F.; Eur. Cells Mater. 2008, 15, 53.

27. Reznikov, N.; Bilton, M.; Lari, L.; Stevens, M. M.; Kröger, R.; Science (80-. ). 2018, 360, eaao2189.

28. Fidler, A. L.; Boudko, S. P.; Rokas, A.; Hudson, B. G.; J. Cell Sci. 2018, $131, \mathrm{jcs} 203950$.

29. Shoulders, M. D.; Raines, R. T.; Annu Rev Biochem 2010, 78, 929.

30. Orgel, J. P. R. O.; Irving, T. C.; Miller, A.; Wess, T. J.; Proc. Natl. Acad. Sci. U. S. A. 2006, 103, 9001.

31. Kadler, K. E.; Int. J. Exp. Pathol. 2017, $98,4$.

32. Petruska, J. A.; Hodge, A. J.; Proc. Natl. Acad. Sci. 1964, 51, 871.

33. Leikina, E.; Mertts, M. V.; Kuznetsova, N.; Leikin, S.; Proc. Natl. Acad. Sci. U. S. A. 2002, 99, 1314.

34. Giraud-Guille, M. M.; Mosser, G.; Belamie, E.; Curr. Opin. Colloid Interface Sci. 2008, 13, 303.

35. Fratzl, P.; Curr. Opin. Colloid Interface Sci. 2003, 8, 32.

36. Robison, R.; Soames, K. M.; Biochem. J. 1924, 18, 740.

37. Weiner, S.; Traub, W.; FEBS Lett. 1986, 206, 262.

38. Traub, W.; Arad, T.; Weiner, S.; Proc. Natl. Acad. Sci. 1989, 86, 9822.

39. McEwen, B. F.; Song, M. J.; Landis, W. J.; J. Comput. Assist. Microsc. 1991, 3, 201.

40. Jiao, K.; Niu, L. N.; Ma, C. F.; Huang, X. Q.; Pei, D. D.; Luo, T.; Huang, Q.; Chen, J. H.; Tay, F. R.; Adv. Funct. Mater. 2016, 26, 6858.

41. Nudelman, F.; Lausch, A. J.; Sommerdijk, N. A. J. M.; Sone, E. D.; J. Struct. Biol. 2013, 183, 258.

42. Landis, W. J.; Song, M. J.; Leith, A.; McEwen, L.; McEwen, B. F.; J. Struct. Biol. 1993, 110, 39.

43. Landis, W. J.; Hodgens, K. J.; Arena, J.; Song, M. J.; McEwen, B. F.; Microsc. Res. Tech. 1996, 33, 192.

44. Xu, Z.; Yang, Y.; Zhao, W.; Wang, Z.; Landis, W. J.; Cui, Q.; Sahai, N.; Biomaterials 2015, 39, 59.

45. Silver, F. H.; Landis, W. J.; Connect. Tissue Res. 2011, 52, 242.

46. Boonrungsiman, S.; Gentleman, E.; Carzaniga, R.; Evans, N. D. McComb, D. W.; Porter, A. E.; Stevens, M. M.; Proc. Natl. Acad. Sci. 2012, 109, 14170.

47. Kerschnitzki, M.; Akiva, A.; Ben Shoham, A.; Asscher, Y.; Wagermaier, W.; Fratzl, P.; Addadi, L.; Weiner, S.; J. Struct. Biol. 2016, 195, 82

48. Mahamid, J.; Aichmayer, B.; Shimoni, E.; Ziblat, R.; Li, C.; Siegel, S.; Paris, O.; Fratzl, P.; Weiner, S.; Addadi, L.; Proc. Natl. Acad. Sci. 2010 107, 6316

49. Heiss, A.; Pipich, V.; Jahnen-Dechent, W.; Schwahn, D.; Biophys. J. 2010, 99, 3986.

50. Jahnen-Dechent, W.; Büscher, A.; Köppert, S.; Heiss, A.; Kuro-o, M.; Smith, E. R.; J. Struct. Biol. 2020, 212.

51. Wang, Y.; Azaïs, T.; Robin, M.; Vallée, A.; Catania, C.; Legriel, P.; Pehau-Arnaudet, G.; Babonneau, F.; Giraud-Guille, M.-M.; Nassif, N.; Nat. Mater. 2012, 11, 724.

52. Silvent, J.; Robin, M.; Bussola Tovani, C.; Wang, Y.; Soncin, F.; Delgado, S.; Azaïs, T.; Sassoye, C.; Giraud-Guille, M.-M.; Sire, J.; Nassif, N.; Biomacromolecules 2021, acs. biomac.1c00206

53. Termine, J. D.; Posner, A. S.; Science (80-. ). 1966, 153, 1523.

54. Termine, J. D.; Posner, A. S.; Arch. Biochem. Biophys. 1970, 140, 307.

55. Eanes, E. D.; Gillessen, I. H.; Posner, A. S.; Nature 1965, 208, 365.

56. Posner, A. S.; Betts, F.; Blumenthal, N. C.; Metab. Bone Dis. Relat. Res. 1978, $1,179$.

57. Dey, A.; Bomans, P. H.; Muller, F. A.; Will, J.; Frederik, P. M.; de With, G.; Sommerdijk, N. A.; Nat. Mater. 2010, 9, 1010.

58. Zhao, W.; Wang, Z.; Xu, Z.; Sahai, N.; Phys. Chem. Chem. Phys. 2018 , $20,13047$.

59. Mancardi, G.; Hernandez Tamargo, C. E.; Di Tommaso, D.; de Leeuw, N. H.; J. Mater. Chem. B 2017, 5, 7274.

60. Mancardi, G.; Terranova, U.; De Leeuw, N. H.; Cryst. Growth Des. 2016, 16, 3353.
61. Yang, X.; Wang, M.; Yang, Y.; Cui, B.; Xu, Z.; Yang, X.; Phys. Chem. Chem. Phys. 2019, 21, 14530.

62. Akiva, A.; Kerschnitzki, M.; Pinkas, I.; Wagermaier, W.; Yaniv, K.; Fratzl, P.; Addadi, L.; Weiner, S.; J. Am. Chem. Soc. 2016, 138, 14481.

63. Mahamid, J.; Sharir, A.; Addadi, L.; Weiner, S.; Proc. Nat. Acad. Sci. USA 2008, 105, 12748.

64. Weiner, S.; Mahamid, J.; Politi, Y.; Ma, Y.; Addadi, L.; Front. Mater. Sci. China 2009, 3, 104.

65. George, A.; Veis, A.; Chem. Rev. 2008, 108, 4670.

66. McKee, M. D.; Nanci, a; Microsc. Res. Tech. 1996, 33, 141.

67. Boskey, A. L.; Villarreal-Ramirez, E.; Matrix Biol. 2016, 52-54, 43.

68. Orgel, J. P. R. O.; San Antonio, J. D.; Antipova, O.; Connect. Tissue Res. 2011, 52, 2 .

69. Sweeney, S. M.; Orgel, J. P.; Fertala, A.; McAuliffe, J. D.; Turner, K. R.; Di Lullo, G. A.; Chen, S.; Antipova, O.; Perumal, S.; Ala-Kokko, L.; Forlino, A.; Cabral, W. A.; Barnes, A. M.; Marini, J. C.; San Antonio, J. D.; J. Biol. Chem. 2008, 283, 21187.

70. Tavafoghi, M.; Cerruti, M.; J. R. Soc. Interface 2016, 13, 1.

71. Oosterlaken, B. M.; Vena, M. P.; de With, G.; Adv. Mater. 2021, 2004418.

72. Olszta, M. J.; Cheng, X.; Jee, S. S.; Kumar, R.; Kim, Y.-Y.; Kaufman, M. J.; Douglas, E. P.; Gower, L. B.; Mater. Sci. Eng. R Reports 2007 $58,77$.

73. Nudelman, F.; Pieterse, K.; George, A.; Bomans, P. H. H.; Friedrich, H.; Brylka, L. J.; Hilbers, P. A. J.; de With, G.; Sommerdijk, N. A. J. M.; Nat. Mater. 2010, 9, 1004

74. Niu, L.; Jee, S. E.; Jiao, K.; Tonggu, L.; Li, M.; Wang, L.; Yang, Y.; Bian, J.; Breschi, L.; Jang, S. S.; Chen, J.; Pashley, D. H.; Tay, F. R.; Nat. Mater. 2016, 1,1 .

75. Shao, C.; Zhao, R.; Jiang, S.; Yao, S.; Wu, Z.; Jin, B.; Yang, Y.; Pan, H.; Tang, R.; Adv. Mater. 2018, 30, 1704876.

76. Deshpande, A. S.; Beniash, E.; Cryst. Growth Des. 2008, 8, 3084.

77. Thrivikraman, G.; Athirasala, A.; Gordon, R.; Zhang, L.; Bergan, R.; Keene, D. R.; Jones, J. M.; Xie, H.; Chen, Z.; Tao, J.; Wingender, B.; Gower, L.; Ferracane, J. L.; Bertassoni, L. E.; Nat. Commun. 2019, 10 .

78. Yao, S.; Lin, X.; Xu, Y.; Chen, Y.; Qiu, P.; Shao, C.; Jin, B.; Mu, Z.; Sommerdijk, N. A. J. M.; Tang, R.; Adv. Sci. 2019, 6.

79. Toroian, D.; Joo, E. L.; Price, P. A.; J. Biol. Chem. 2007, 282, 22437.

80. Ma, Y. xuan; Hoff, S. E.; Huang, X. qing; Liu, J.; Wan, Q. qian; Song, Q.; Gu, J. ting; Heinz, H.; Tay, F. R.; Niu, L. na; Acta Biomater. 2021, 120, 213.

81. Goldstein, D. A.; Serum Calcium; 1990.

82. Bansal, V. K.; Serum Inorganic Phosphorus; 1990.

83. Reznikov, N.; Steele, J. A. M.; Fratzl, P.; Stevens, M. M.; Nat. Rev. Mater. 2016, $1,16041$.

84. Xu, Z.; Yang, Y.; Zhao, W.; Wang, Z.; Landis, W. J.; Cui, Q.; Sahai, N.; Biomaterials 2015, 39, 59.

85. Murshed, M.; Harmey, D.; Millán, J. L.; McKee, M. D.; Karsenty, G.; Genes Dev. 2005, 19, 1093.

86. Fleisch, H.; Russel, R. G. G.; Straumann, F.; Nature 1966, 212, 901.

87. Orriss, I. R.; Bone 2020, 134

88. Millán, J. L.; Calcif. Tissue Int. 2013, 93, 299.

89. Thouverey, C.; Bechkoff, G.; Pikula, S.; Buchet, R.; Osteoarthr. Cartil. 2009, 17, 64 .

90. Garimella, R.; Bi, X.; Anderson, H. C.; Camacho, N. P.; Bone 2006, 38, 811.

91. Hoac, B.; Kiffer-Moreira, T.; Millán, J. L.; McKee, M. D.; Bone 2013, 53,478

92. Heiss, A.; Pipich, V.; Jahnen-Dechent, W.; Schwahn, D.; Biophys. J. 2010, 99, 3986.

93. Jahnen-Dechent, W.; Schäfer, C.; Ketteler, M.; McKee, M. D.; J. Mol. Med. 2008, 86, 379 
94. Jahnen-Dechent, W.; Heiss, A.; Schäfer, C.; Ketteler, M.; Circ. Res. 2011, 108, 1494.

95. Akiva, A.; Nelkenbaum, O.; Schertel, A.; Yaniv, K.; Weiner, S.; Addadi, L.; J. Struct. Biol. 2019, 206, 139.

96. Kerschnitzki, M.; Akiva, A.; Shoham, A. Ben; Koifman, N.; Shimoni, E.; Rechav, K.; Arraf, A. A.; Schultheiss, T. M.; Talmon, Y.; Zelzer, E.; Weiner, S.; Addadi, L.; Bone 2016, 83, 65.

97. Pei, D. dan; Sun, J. long; Zhu, C. hui; Tian, F. cong; Jiao, K.; Anderson, M. R.; Yiu, C.; Huang, C.; Jin, C. xiong; Bergeron, B. E.; Chen, J. hua; Tay, F. R.; Niu, L. na; Adv. Sci. 2018, 5.

98. Mahamid, J.; Sharir, A.; Gur, D.; Zelzer, E.; Addadi, L.; Weiner, S.; J. Struct. Biol. 2011, 174, 527.

99. Bottini, M.; Mebarek, S.; Anderson, K. L.; Strzelecka-Kiliszek, A.; Bozycki, L.; Simão, A. M. S.; Bolean, M.; Ciancaglini, P.; Pikula, J. B.; Pikula, S.; Magne, D.; Volkmann, N.; Hanein, D.; Millán, J. L.; Buchet, R.; Biochim. Biophys. Acta - Gen. Subj. 2018, 1862, 532.

100. Van Niel, G.; D’Angelo, G.; Raposo, G.; Nat. Rev. Mol. Cell Biol. 2018, 19, 213.

101. Anderson, H. C.; J. Cell Biol. 1967, 35, 81.

102. Bonucci, E.; J. Ultrastruct. Res. 1967, 20, 33.

103. Wuthier, R. E.; Lipscomb, G. F.; Front. Biosci. (Landmark Ed. 2011, 16, 2812.

104. Anderson, H. C.; Sipe, J. B.; Hessle, L.; Dhamyamraju, R.; Atti, E.; Camacho, N. P.; Millán, J. L.; Am. J. Pathol. 2004, 164, 841.

105. Balcerzak, M.; Radisson, J.; Azzar, G.; Farlay, D.; Boivin, G.; Pikula, S.; Buchet, R.; Anal. Biochem. 2007, 361, 176.

106. Chaudhary, S. C.; Kuzynski, M.; Bottini, M.; Beniash, E.; Dokland, T.; Mobley, C. G.; Yadav, M. C.; Poliard, A.; Kellermann, O.; Millán, J. L.; Napierala, D.; Matrix Biol. 2016, 52-54, 284.

107. Abdallah, D.; Hamade, E.; Merhi, R. A.; Bassam, B.; Buchet, R.; Mebarek, S.; Biochem. Biophys. Res. Commun. 2014, 446, 1161.

108. Thouverey, C.; Strzelecka-Kiliszek, A.; Balcerzak, M.; Buchet, R.; Pikula, S.; J. Cell. Biochem. 2009, 106, 127.

109. Simão, A. M. S.; Bolean, M.; Favarin, B. Z.; Veschi, E. A.; Tovani, C. B.; Ramos, A. P.; Bottini, M.; Buchet, R.; Millán, J. L.; Ciancaglini, P.; J. Bone Miner. Metab. 2019, 37, 607.

110. Camolezi, F. L.; Daghastanli, K. R. P.; Magalhães, P. P.; Pizauro, J. M.; Ciancaglini, P.; Int. J. Biochem. Cell Biol. 2002, 34, 1091.

111. Derradi, R.; Bolean, M.; Simão, A. M. S.; Caseli, L.; Millán, J. L.; Bottini, M.; Ciancaglini, P.; Ramos, A. P.; Langmuir 2019, 35, 15232.

112. Favarin, B. Z.; Bolean, M.; Ramos, A. P.; Magrini, A.; Rosato, N.; Millán, J. L.; Bottini, M.; Costa-Filho, A. J.; Ciancaglini, P.; Arch. Biochem. Biophys. 2020, 108482.

113. Bolean, M.; Simão, A. M. S.; Favarin, B. Z.; Millán, J. L.; Ciancaglini, P.; Biophys. Chem. 2011, 158, 111.

114. Bolean, M.; Simão, A. M. .; Favarin, B. Z.; Millán, J. L.; Ciancaglini, P.; Biophys. Chem. 2010, 152, 74.

115. Simão, A. M. S.; Bolean, M.; Hoylaerts, M. F.; Millán, J. L.; Ciancaglini, P.; Calcif. Tissue Int. 2013, 93, 222.

116. Ierardi, D. F.; Pizauro, J. M.; Ciancaglini, P.; Biochim. Biophys. Acta Biomembr. 2002, 1567, 183.

117. Irving, J. T.; Wuthier, R. E.; Clin. Orthop. Relat. Res. 1968, 56, 237.

118. Wuthier, R. E.; Calcif. Tissue Res. 1969, 4, 20.

119. Wuthier, R. E.; Calcif. Tissue Res. 1971, 8, 36.

120. Cotmore, J. M.; Nichols, G.; Wuthier, R. E.; Science (80-. ). 1971, 172, 1339.

121. Anghileri, L. J.; Dermietzel, R.; Zeitschrift für Krebsforsch. und Klin. Onkol. 1973, 79, 148.

122. Boskey, A. L.; Posner, A. S.; Calcif. Tissue Res. 1975, 19, 273.

123. McLean, F. M.; Keller, P. J.; Genge, B. R.; Walters, S. A.; Wuthier, R. E.; J. Biol. Chem. 1987, 262, 10481.

124. Register, T. C.; Mclean, F. M.; Lows, M. G.; Wuthier, R. E.; J. Biol. Chem. 1986, 261, 9354.
125. Wu, L.; Genge, B. R.; Dunkelberger, D. G.; LeGeros, R. Z.; Concannon, B.; Wuthier, R. E.; J. Biol. Chem. 1997, 272, 4404.

126. Cruz, M. A. E.; Ferreira, C. R.; Tovani, C. B.; de Oliveira, F. A.; Bolean, M.; Caseli, L.; Mebarek, S.; Luis Millán, J.; Buchet, R.; Bottini, M.; Ciancaglini, P.; Paula Ramos, A.; J. Struct. Biol. 2020, 212, 107607.

127. Goettsch, C.; Strzelecka-Kiliszek, A.; Bessueille, L.; Quillard, T.; Mechtouff, L.; Pikula, S.; Canet-Soulas, E.; Millan, J. L.; Fonta, C.; Magne, D.; Cardiovasc. Res. 2020, 1.

128. Le Du, M.-H.; Millán, J. L.; J. Biol. Chem. 2002, 277, 49808.

129. Millán, J. L.; In Mammalian Alkaline Phosphatases; Wiley-VCH Verlag GmbH \& Co. KGaA: Weinheim, FRG, 2006; pp. 1-2.

130. Millán, J. L.; Purinergic Signal. 2006, 2, 335.

131. Leone, F. A.; Ciancaglini, P.; Pizauro, J. M.; J. Inorg. Biochem. 1997, $68,123$.

132. Hoylaerts, M. F.; Van kerckhoven, S.; Kiffer-Moreira, T.; Sheen, C.; Narisawa, S.; Millán, J. L.; PLoS One 2015, 10, e0119874.

133. de Bernard, B.; Bianco, P.; Bonucci, E.; Costantini, M.; Lunazzi, G. C.; Martinuzzi, P.; Modricky, C.; Moro, L.; Panfili, E.; Pollesello, P.; J. Cell Biol. 1986, 103, 1615.

134. Canet-Soulas, E.; Bessueille, L.; Mechtouff, L.; Magne, D.; Front. Cell Dev. Biol. 2021, 9, 1.

135. Ciancaglini, P.; Yadav, M. C.; Simão, A. M. S.; Narisawa, S.; Pizauro, J. M.; Farquharson, C.; Hoylaerts, M. F.; Millán, J. L.; J. Bone Miner. Res. 2010, 25, 716.

136. Chan, J. R. A.; Stinson, R. A.; J. Biol. Chem. 1986, 261, 7635.

137. Narisawa, S.; Yadav, M. C.; Millán, J. L.; J. Bone Miner. Res. 2013, 28 , 1587.

138. Harmey, D.; Johnson, K. A.; Zelken, J.; Camacho, N. P.; Hoylaerts, M. F.; Noda, M.; Terkeltaub, R.; Millán, J. L.; J. Bone Miner. Res. 2006, 21, 1377.

139. Millán, J. L.; Whyte, M. P.; Calcif. Tissue Int. 2016, 98, 398.

140. Whyte, M. P.; Rockman-Greenberg, C.; Ozono, K.; Riese, R.; Moseley, S.; Melian, A.; Thompson, D. D.; Bishop, N.; Hofmann, C.; J. Clin. Endocrinol. Metab. 2016, 101, 334.

141. Millán, J. L.; Plotkin, H.; Actual. osteol. 2012, 8, 164.

142. Zimmermann, H.; Zebisch, M.; Sträter, N.; Purinergic Signal. 2012, 8, 437.

143. Stefan, C.; Jansen, S.; Bollen, M.; Trends Biochem. Sci. 2005, 30, 542.

144. Simão, A. M. S.; Yadav, M. C.; Narisawa, S.; Bolean, M.; Pizauro, J. M.; Hoylaerts, M. F.; Ciancaglini, P.; Millán, J. L.; J. Biol. Chem. 2010, 285, 7598.

145. Hessle, L.; Johnson, K. a; Anderson, H. C.; Narisawa, S.; Sali, A.; Goding, J. W.; Terkeltaub, R.; Millan, J. L.; Proc. Natl. Acad. Sci. U. S. A. 2002, 99, 9445.

146. Yadav, M. C.; Bottini, M.; Cory, E.; Bhattacharya, K.; Kuss, P.; Narisawa, S.; Sah, R. L.; Beck, L.; Fadeel, B.; Farquharson, C.; Millán, J. L.; J. Bone Miner. Res. 2016, 31, 1275.

147. Johnson, K.; Hashimoto, S.; Lotz, M.; Pritzker, K.; Goding, J.; Terkeltaub, R.; Arthritis Rheum. 2001, 44, 1071.

148. Sun, Y.; Mauerhan, D. R.; Honeycutt, P. R.; Kneisl, J. S.; Norton, H. J.; Zinchenko, N.; Hanley, E. N.; Gruber, H. E.; Arthritis Res. Ther. 2010, 12.

149. Roberts, S. J.; Stewart, A. J.; Sadler, P. J.; Farquharson, C.; Biochem. J. 2004, 382, 59.

150. Houston, B.; Stewart, A. J.; Farquharson, C.; Bone 2004, 34, 629.

151. Yadav, M. C.; Simão, A. M. S.; Narisawa, S.; Huesa, C.; McKee, M. D.; Farquharson, C.; Millán, J. L.; J. Bone Miner. Res. 2011, 26, 286.

152. Dillon, S.; Staines, K. A.; Millán, J. L.; Farquharson, C.; JBMR Plus 2019, 3, e10202.

153. Beck, L.; Pflugers Arch. Eur. J. Physiol. 2019, 471, 175.

154. Palmer, G.; Zhao, J.; Bonjour, J.; Hofstetter, W.; Caverzasio, J.; Bone 1999, 24,1 .

155. Beck, G. R.; J. Cell. Biochem. 2003, 90, 234. 
156. Sugita, A.; Kawai, S.; Hayashibara, T.; Amano, A.; Ooshima, T.; Michigami, T.; Yoshikawa, H.; Yoneda, T.; J. Biol. Chem. 2011, 286, 3094.

157. Lau, W. L.; Festing, M.; Giachelli, C.; Thromb. Haemost. 2010, 104, 464.

158. Suzuki, A.; Ammann, P.; Nishiwaki-Yasuda, K.; Sekiguchi, S.; Asano, S.; Nagao, S.; Kaneko, R.; Hirabayashi, M.; Oiso, Y.; Itoh, M.; Caverzasio, J.; J. Bone Miner. Metab. 2010, 28, 139.

159. Suzuki, A.; Ammann, P.; Nishiwaki-Yasuda, K.; Sekiguchi, S.; Asano, S.; Nagao, S.; Kaneko, R.; Hirabayashi, M.; Oiso, Y.; Itoh, M.; Caverzasio, J.; J. Bone Miner. Metab. 2010, 28, 139.

160. Hsu, H. H. T.; Clarke Anderson, H.; J. Biol. Chem. 1996, 271, 26383.

161. Yoneda, J. S.; Sebinelli, H. G.; Itri, R.; Ciancaglini, P.; Biophys. Rev. 2020, 12, 49.

162. Kaplan, J. H.; Annu. Rev. Biochem. 2002, 71, 511.

163. Morth, J. P.; Pedersen, B. P.; Toustrup-Jensen, M. S.; Sørensen, T. L.-M.; Petersen, J.; Andersen, J. P.; Vilsen, B.; Nissen, P.; Nature 2007, 450, 1043.

164. Clausen, M. V.; Hilbers, F.; Poulsen, H.; Front. Physiol. 2017, 8, 1.

165. Balcerzak, M.; Malinowska, A.; Thouverey, C.; Sekrecka, A.; Dadlez, M.; Buchet, R.; Pikula, S.; Proteomics 2008, 8, 192.

166. Thouverey, C.; Malinowska, A.; Balcerzak, M.; Strzelecka-Kiliszek, A.; Buchet, R.; Dadlez, M.; Pikula, S.; J. Proteomics 2011, 74, 1123.

167. Nakano, Y.; Addison, W. N.; Kaartinen, M. T.; Bone 2007, 41, 549.

168. Strzelecka-Kiliszek, A.; Buszewska, M. E.; Podszywalow-Bartnicka, P.; Pikula, S.; Otulak, K.; Buchet, R.; Bandorowicz-Pikula, J.; J. Cell. Biochem. 2008, 104, 418.

169. Genetos, D. C.; Wong, A.; Weber, T. J.; Karin, N. J.; Yellowley, C. E.; PLoS One 2014, 9, e107482.

170. Bolean, M.; Simão, A. M. S.; Kiffer-Moreira, T.; Hoylaerts, M. F.; Millán, J. L.; Itri, R.; Ciancaglini, P.; Arch. Biochem. Biophys. 2015, $584,79$.

171. Arispe, N.; Rojas, E.; Genge, B. R.; Wu, L. N. Y.; Wuthier, R. E.; Biophys. J. 1996, 71, 1764.

172. Brisson, A.; Mosser, G.; Huber, R.; J. Mol. Biol. 1991, 220, 199.

173. Kirsch, T.; Nah, H. D.; Demuth, D. R.; Harrison, G.; Golub, E. E.; Adams, S. L.; Pacifici, M.; Biochemistry 1997, 36, 3359.

174. Kaneko, N.; Ago, H.; Matsuda, R.; Inagaki, E.; Miyano, M.; J. Mol. Biol. 1997, 274, 16.

175. Wang, W.; Kirsch, T.; J. Cell Biol. 2002, 157, 1061.

176. Kirsch, T.; Swoboda, B.; Nah, H.-D.; Osteoarthr. Cartil. 2000, 8, 294.

177. Bolean, M.; Izzi, B.; van kerckhoven, S.; Bottini, M.; Ramos, A. P.; Millán, J. L.; Hoylaerts, M. F.; Ciancaglini, P.; Biochim. Biophys. Acta - Gen. Subj. 2020, 1864, 129629.

178. von der Mark, K.; Mollenhauer, J.; Cell. Mol. Life Sci. 1997, 53, 539.

179. Veschi, E. A.; Bolean, M.; Strzelecka-Kiliszek, A.; Bandorowicz-Pikula, J.; Pikula, S.; Granjon, T.; Mebarek, S.; Magne, D.; Ramos, A. P.; Rosato, N.; Millán, J. L.; Buchet, R.; Bottini, M.; Ciancaglini, P.; Int. J. Mol. Sci. 2020, 21, 1367.

180. Patel, D. R.; Isas, J. M.; Ladokhin, A. S.; Jao, C. C.; Kim, Y. E.; Kirsch, T.; Langen, R.; Haigler, H. T.; Biochemistry 2005, 44, 2833.

181. Huber, R.; Romisch, J.; Paques, E. P.; EMBO J. 1990, 9, 3867.
182. Wu, L. N. Y.; Genge, B. R.; Dunkelberger, D. G.; LeGeros, R. Z.; Concannon, B.; Wuthier, R. E.; J. Biol. Chem. 1997, 272, 4404.

183. Cmoch, A.; Strzelecka-Kiliszek, A.; Palczewska, M.; Groves, P.; Pikula, S.; Biochem. Biophys. Res. Commun. 2011, 412, 683.

184. Golczak, M.; Kicinska, A.; Pikula, J. B.; Buchet, R.; Szewczyk, A.; Pikula, S.; FASEB J. 2001, 15, 1083.

185. Wu, L. N. Y.; Yoshimori, T.; Genge, B. R.; Sauer, G. R.; Kirsch, T.; Ishikawa, Y.; Wuthier, R. E.; J. Biol. Chem. 1993, 268, 25084.

186. Mebarek, S.; Abousalham, A.; Magne, D.; Do, L. D.; BandorowiczPikula, J.; Pikula, S.; Buchet, R.; Int. J. Mol. Sci. 2013, 14, 5036.

187. Bolean, M.; Simão, A. M. S.; Barioni, M. B.; Favarin, B. Z.; Sebinelli, H. G.; Veschi, E. A.; Janku, T. A. B.; Bottini, M.; Hoylaerts, M. F.; Itri, R.; Millán, J. L.; Ciancaglini, P.; Biophys. Rev. 2017, 9, 747.

188. Ciancaglini, P.; Simão, A. M. S.; Bolean, M.; Millán, J. L.; Rigos, C. F.; Yoneda, J. S.; Colhone, M. C.; Stabeli, R. G.; Biophys. Rev. 2012, 4, 67.

189. Favarin, B. F.; Andrade, M. A. R.; Bolean, M.; Simão, A. M. S.; Ramos, A. P.; Hoylaerts, M. F.; Millán, J. L.; Ciancaglini, P.; Colloids Surfaces B Biointerfaces 2017, 155, 466.

190. Garcia, A. F.; Simão, A. M. S.; Bolean, M.; Hoylaerts, M. F.; Millán, J. L.; Ciancaglini, P.; Costa-Filho, A. J.; Phys. Chem. Chem. Phys. 2015, $17,26295$.

191. Sebinelli, H. G.; Borin, I. A.; Ciancaglini, P.; Bolean, M.; Soft Matter 2019, 15, 2737.

192. Bolean, M.; Borin, I. A.; Simão, A. M. S.; Bottini, M.; Bagatolli, L. A.; Hoylaerts, M. F.; Millán, J. L.; Ciancaglini, P.; Biochim. Biophys. Acta - Biomembr. 2017, 1859, 1911.

193. Di Mauro, S.; Manes, T.; Hessle, L.; Kozlenkov, A.; Pizauro, J. M.; Hoylaerts, M. F.; Millán, J. L.; J. Bone Miner. Res. 2002, 17, 1383.

194. Wei, Y.; Shi, M.; Zhang, J.; Zhang, X.; Shen, K.; Wang, R.; Miron, R. J.; Xiao, Y.; Zhang, Y.; Adv. Funct. Mater. 2020, 2000015, 1.

195. Itel, F.; Skovhus Thomsen, J.; Städler, B.; ACS Appl. Mater. Interfaces 2018, 10, 30180.

196. Rauner, N.; Meuris, M.; Zoric, M.; Tiller, J. C.; Nature 2017, 543, 407.

197. Lanier, M.; Sergienko, E.; Simão, A. M.; Su, Y.; Chung, T.; Millán, J. L.; Cashman, J. R.; Bioorg. Med. Chem. 2010, 18, 573.

198. Caseli, L.; Nobre, T. M.; Ramos, A. P.; Monteiro, D. S.; Zaniquelli, M. E. D.; In Recent Progress in Colloid and Surface Chemistry with Biological Applications; 2015; pp. 65-88.

199. Andrade, M. A. R.; Favarin, B.; Derradi, R.; Bolean, M.; Simão, A. M. S.; Millán, J. L.; Ciancaglini, P.; Ramos, A. P.; Colloids Surfaces A Physicochem. Eng. Asp. 2016, 504, 305.

200. Andrade, M. A. R.; Derradi, R.; Simão, A. M. S.; Millán, J. L.; Ramos, A. P.; Ciancaglini, P.; Bolean, M.; Arch. Biochem. Biophys. 2019, 663, 192.

201. de Wildt, B. W. M.; Ansari, S.; Sommerdijk, N. A. J. M.; Ito, K.; Akiva, A.; Hofmann, S.; Curr. Opin. Biomed. Eng. 2019, 10, 107.

202. Mansoorifar, A.; Subbiah, R.; Balbinot, G. de S.; Parthiban, S. P.; Bertassoni, L. E.; J. Struct. Biol. 2020, 212, 107636.

203. Ramos, A. P.; Bolean, M.; Cruz, M. A. E.; Andrilli, L. H. S.; Nogueira, L. F. B.; Sebinelli, H. G.; dos Santos, A. L. N.; Favarin, B. Z.; Macedo, J. M. M.; Veschi, E. A.; Ferreira, C. R.; Millán, J. L.; Bottini, M.; Ciancaglini, P.; Biophys. Rev. 2021. 